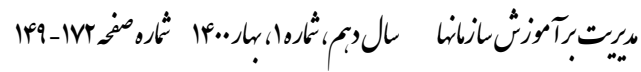

\section{نقش مديريت مشاركتى و مسئوليتيذيرى اجتماعى مديران در رضايت شغلى معلمان متوسطه اول: آزمون ميانجى}

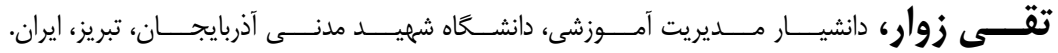 \\ *ـــــروين بــــهارى، كارشنــاس ارشد تحقيقات آموزشى. دانشخاه شهيد مدنى آذربايجان، تبريز، ايران. \\ صياد عبداللى اصل، كارشناس ارشد تحقيقات آموزشى. دانشگاه شهيد مدنى آذربايجان، تبريز، ايران. \\ واقف دلخوش، كارشناس ارشد تحقيقات آموزشى. دانشعاه شهيد مدنى آذربايجان، تبريز، ايران.
}

جكيده

هدف يزوهش حاضر بررسى نقش ميانجى

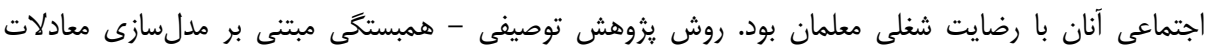

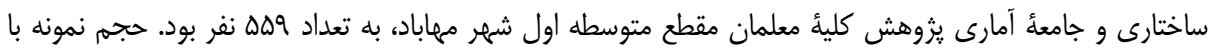

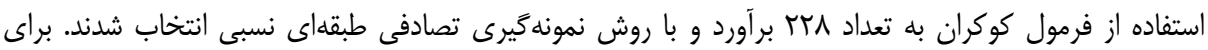

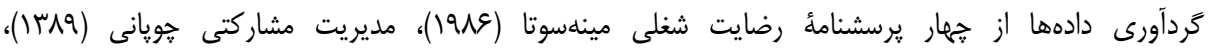

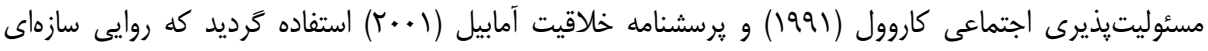

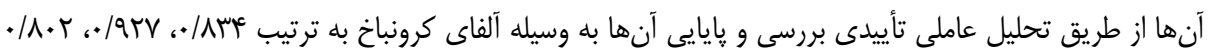
و ؤV/ • بهدست آمد. به منظور تحليل دادهها از دو نرم افزار SPSS23 و

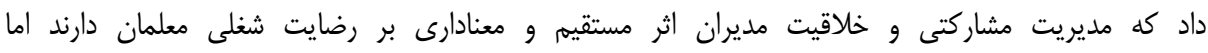

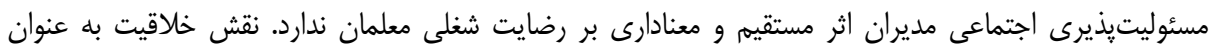

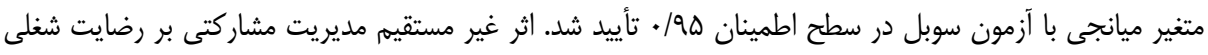

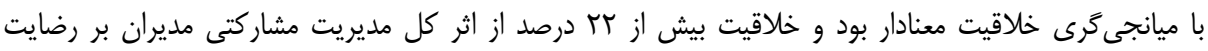

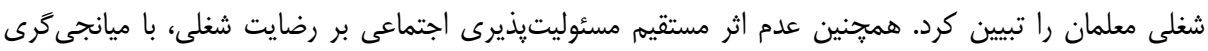

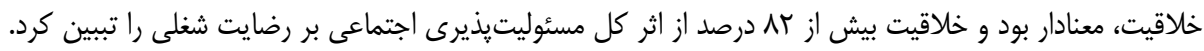

وازَّان كليدى: رضايت شغلى، مديريت مشار كتى، مسئوليتيذيرى اجتماعى، خلاقيت مديران.

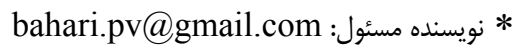

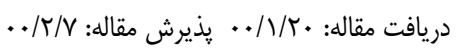




\title{
The role of participatory management and social responsibility of principals in First high school teacher's job satisfaction: creativity mediation test of principals
}

\author{
Taghi Zavvar, Associate Professor Educational Administration, Azarbaijan \\ Shahid Madani University, Tabriz, Iran. \\ *Parvin Bahari, M. A in Educational Research, Azarbaijan Shahid Madani \\ University, Tabriz, Iran.
}

Sayyad Abdollahi Asl, M. A in Educational Research, Azarbaijan Shahid Madani University, Tabriz, Iran.

Vaghef Delkhosh, M. A in Educational Research, Azarbaijan Shahid Madani University, Tabriz, Iran.

\begin{abstract}
The purpose of this study was to investigate the mediating role of Managers creativity in the in the relationship between Managers participatory management and social responsibility with teacher's job satisfaction. The sample size was determined using Cochran's formula to 228 people and be selected with using relative stratified random sampling method. Data were collected using four questionnaires: job satisfaction Minnesota (1986), Choupani participatory management (2011), Carroll's social responsibility (1991) and Amabile creative questionnaire (2001); their construct validity were evaluated by the confirmatory factor analysis and the reliability by alpha Cronbach was $0.834,0.927,0.802$ and 0.746, respectively. For data analysis Spss23 and Amos23 software were used. The results of data analysis indicated the Participatory management and creativity of principals have a direct and significant effect on teachers' job satisfaction. But the social responsibility of principals did not have a direct and significant effect on teachers' job satisfaction. The role of creativity as mediating variable With the Sobel test in the were confirmed tconfidence level of 0.95 . The indirect effect of participatory management on job satisfaction mediated by creativity was significant and the creativity of principals more than $22 \%$ of the total effect participatory management on job satisfaction. Also the lack of direct effect of social responsibility on job satisfaction, mediated by creativity, was significant and creativity explained more than $82 \%$ of the total effect social responsibility on job satisfaction.
\end{abstract}

Keywords: job satisfaction, participatory management, social responsibility, creativity of principals.

* Corresponding author: bahari.pv@gmail.com

Receiving Date: 9/4/2021 Acceptance Date: 27/4/2021 
مقدمه

آموزش و يرورش از جملهى مهمترين و وسيعترين نظامهاى جامعه به شمار مىآيد كه مسئوليت

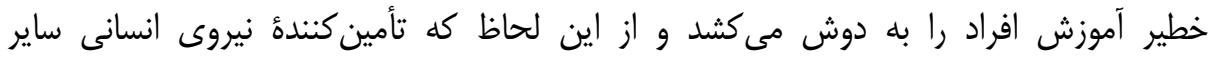

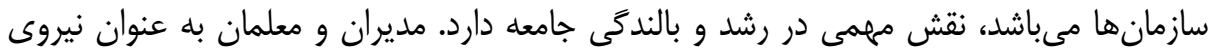

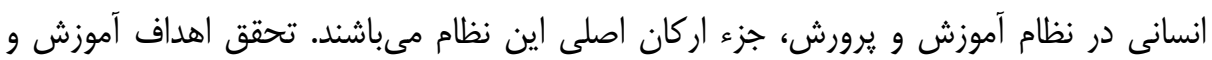

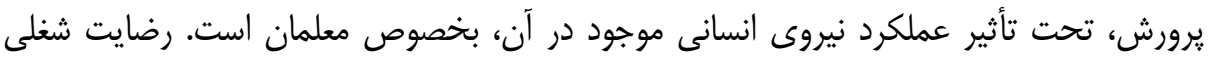

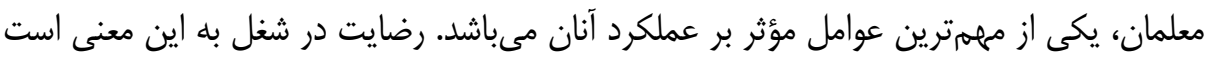

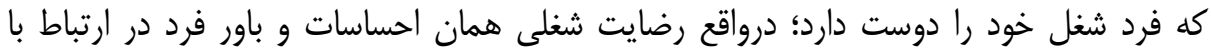

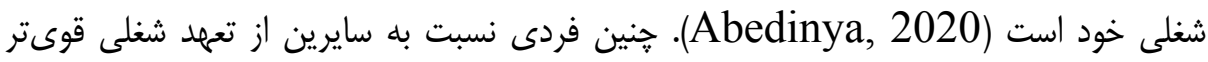

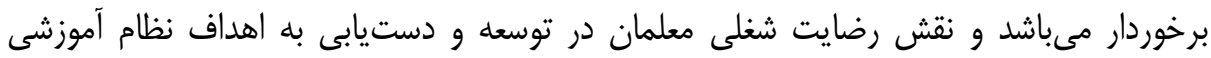

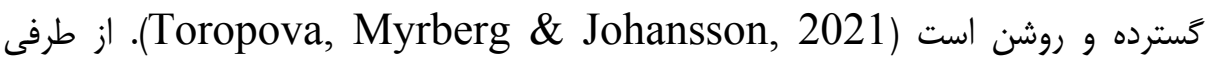

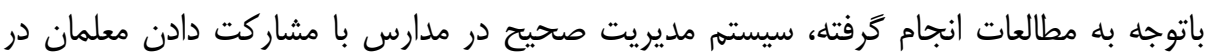

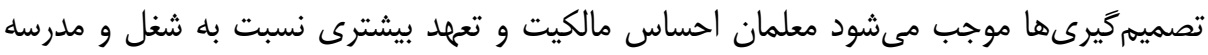
داشته باشند؛ اين احساسات مثبت مىتواند رضايت شغلى معلمان را ارتقاء دهد ) Brezicha et

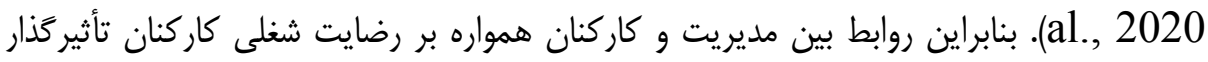
است (Hee et al., 2018).

رضايت شغلى ا واكنش احساسى و عاطفى نسبت به وضعيت شغلى و كار شخص است و

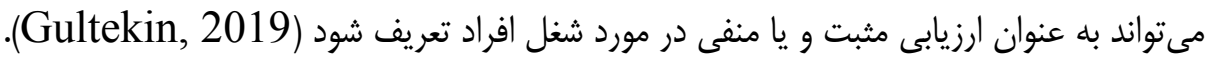

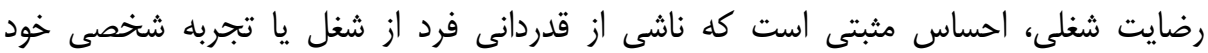

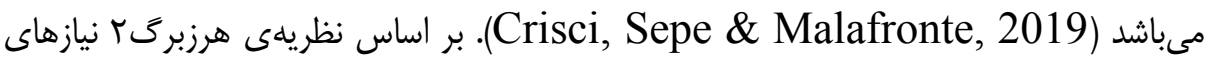

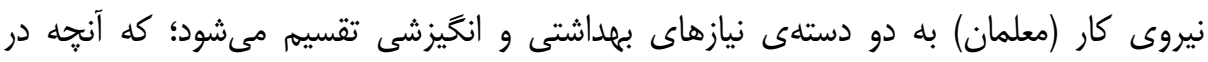

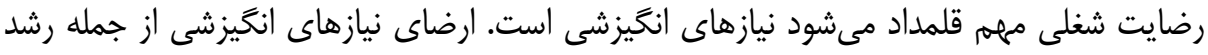

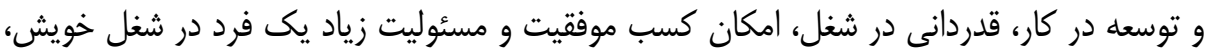

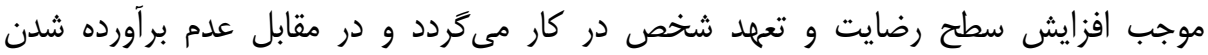

1. job Satisfaction

2. Herzberg 
Sepahmansoor, ) نيازهاى انخيزشى موجب نارضايتى و خستخى از محيط كار مىشود .Shahriaariahmadi \& Shahaami, 2012

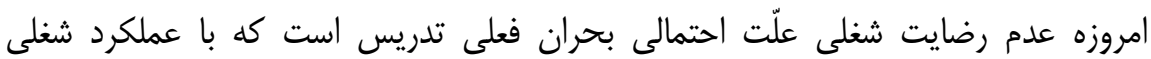

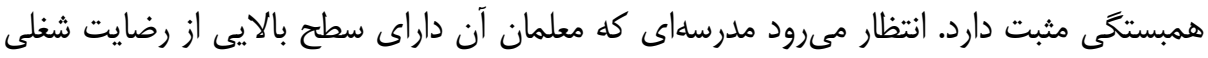

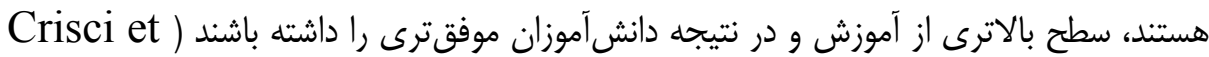

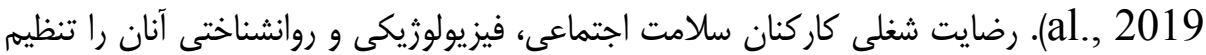

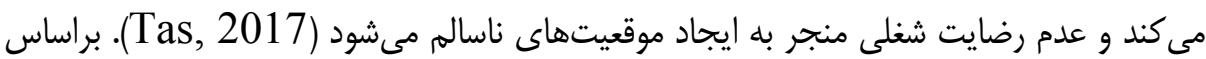

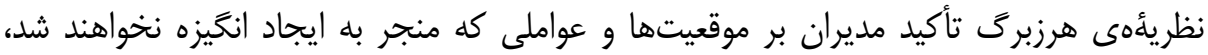

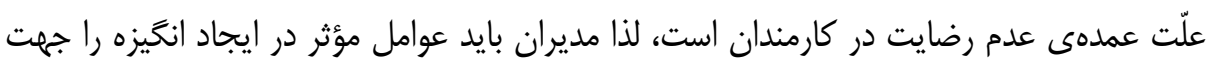

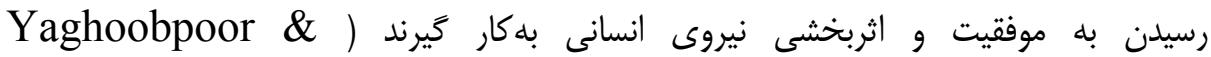

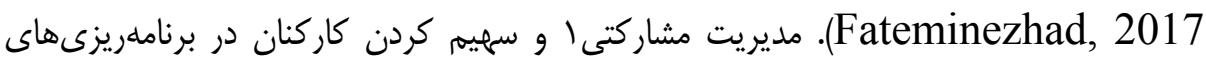

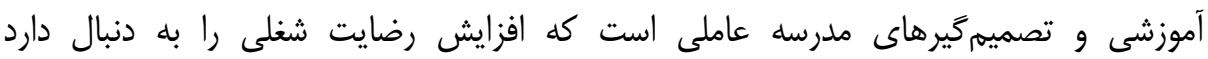
.(Akbari \& Amirmahmoudi, 2016)

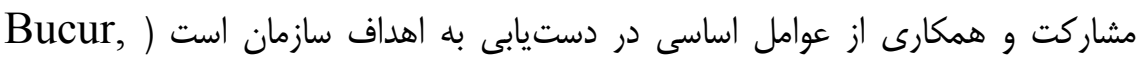

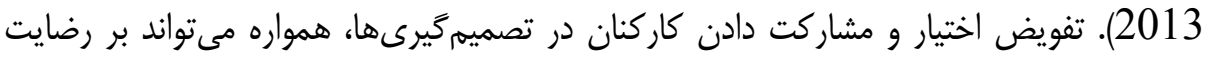

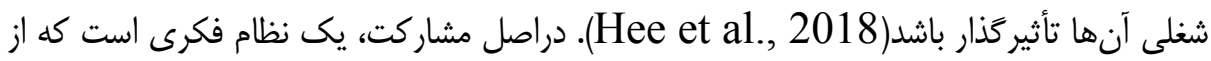
طريق تعليم و تربيت در جامعله نهادينه مى شود (NaderiBoni et al., 2020).

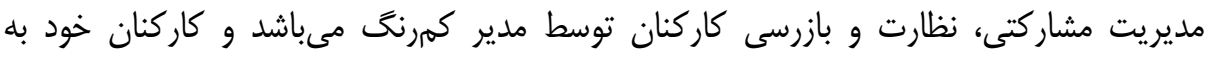

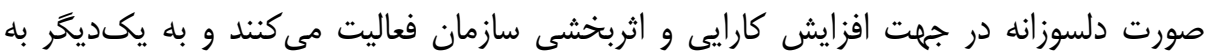

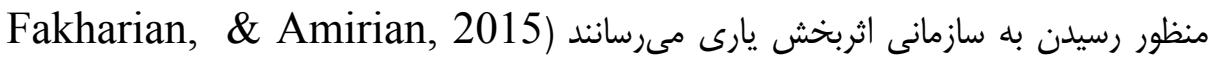

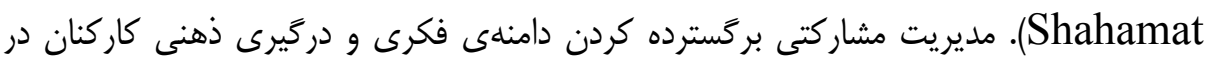

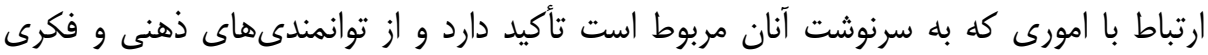

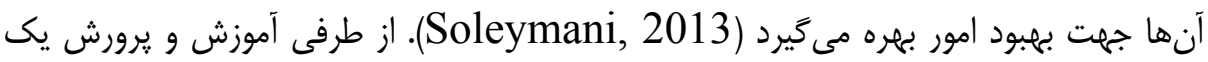

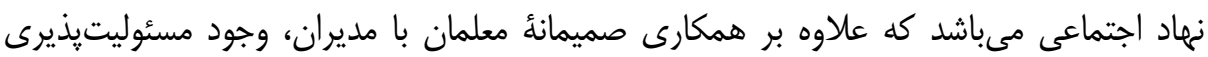

1. participatory management 
نقش مديريت مشاركتى و .... زوار، بهارى، عبدالهى اصل، دلخوش

Asrar-ul-Haq, ) اجتماعى مديران آن نيز مىتواند در رضايت شغلى معلمان تأثير كذار باشد)

.Kuchinke \& Iqbal, 2017

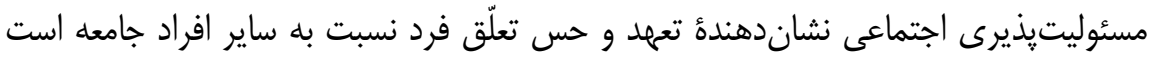

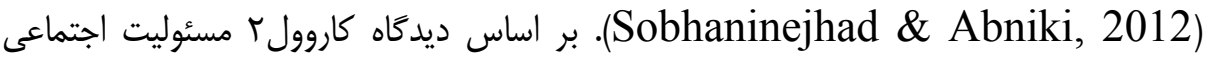

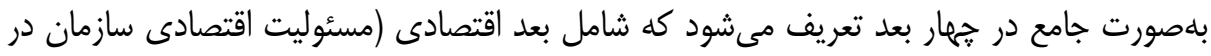

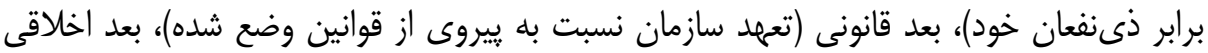

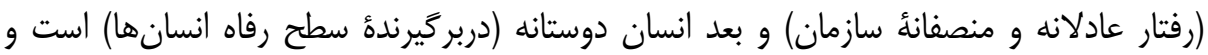

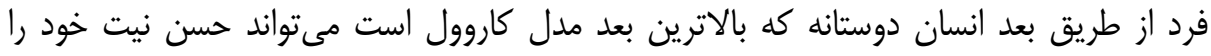

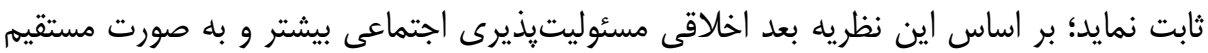

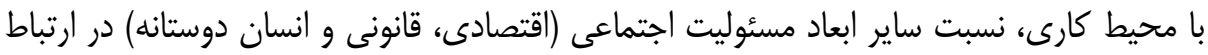

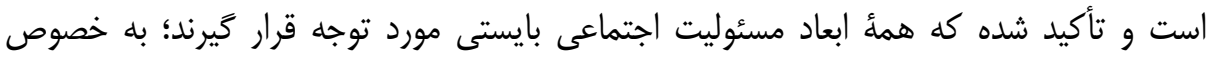

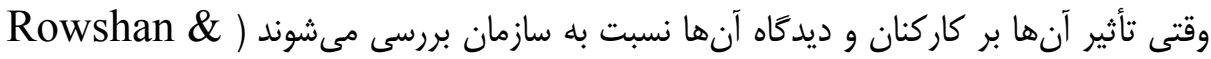

.Farzaneh Hassanzadeh, 2014

فراتر از روابط مستقيم ذكر شده؛ بهنظر مىرسد با توجه به نتايج مطالعات انجام گرفتنه كه

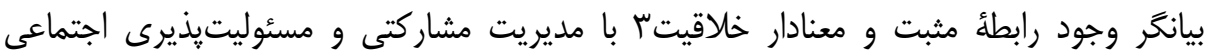

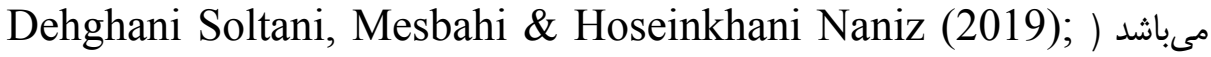

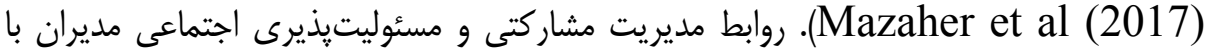

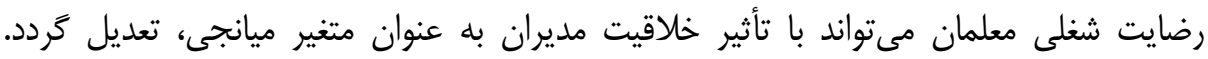

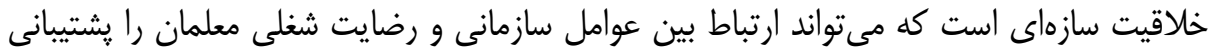

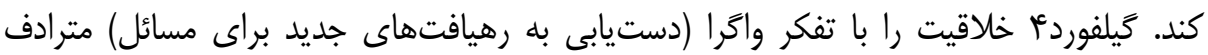

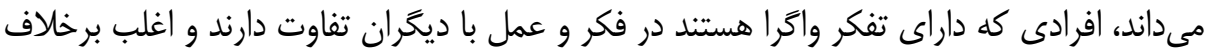

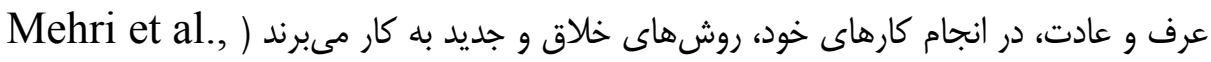

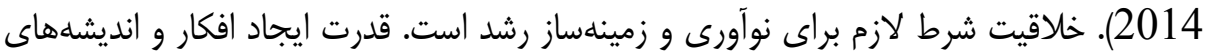

1. social responsibility

2. Carroll

3. creativity

4. Guilford 
Mirkamali, Romiani \& ) جديد و بهكارگيرى آن افكار و انديشههاى نو خلاقيت نام دارد

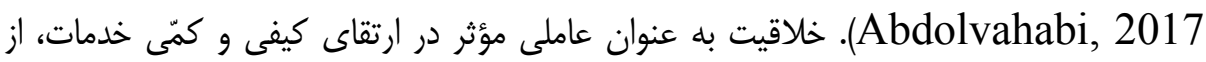

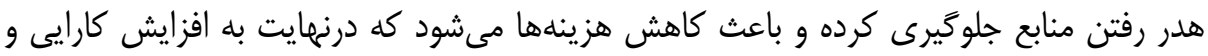

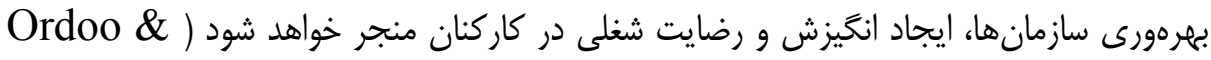

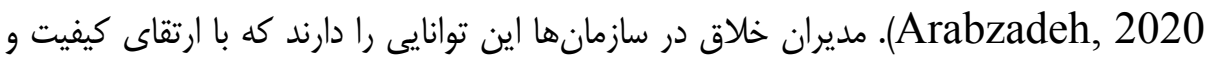

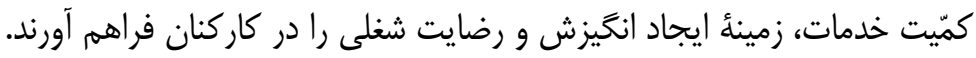

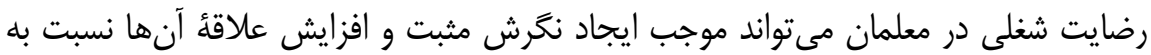

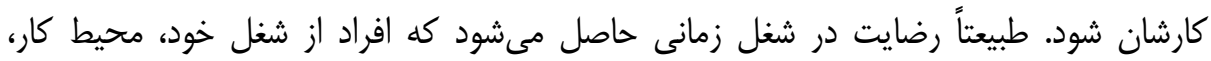

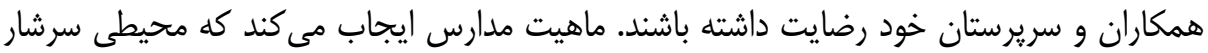

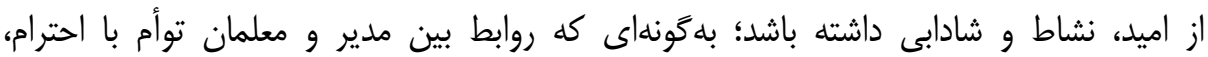

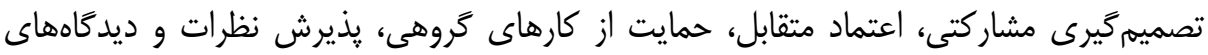

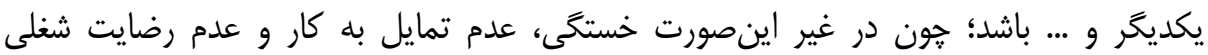

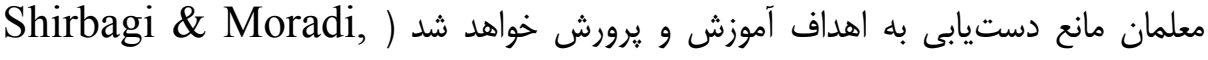

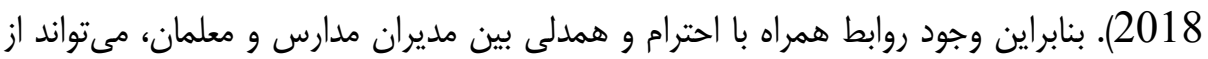

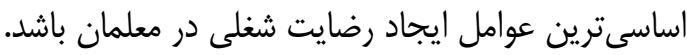

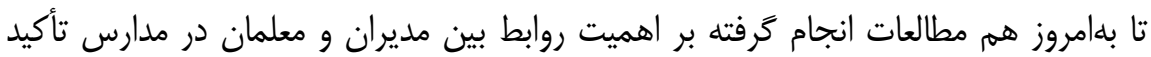

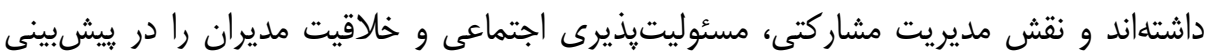

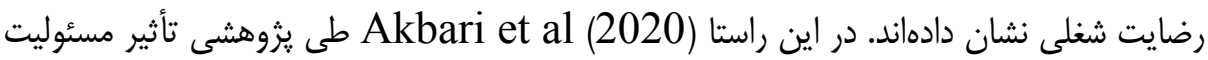

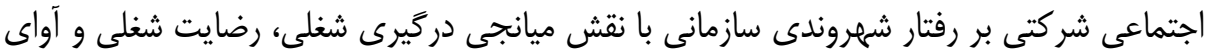

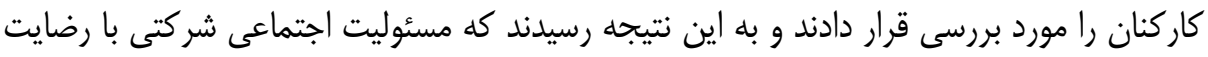

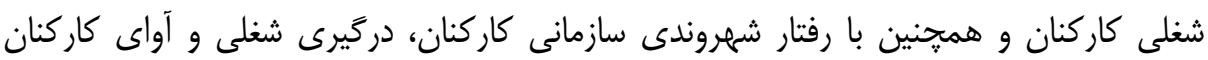

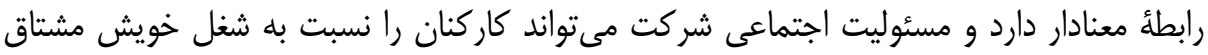

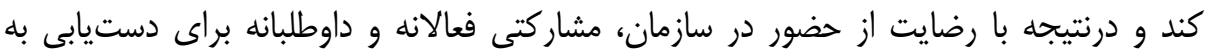

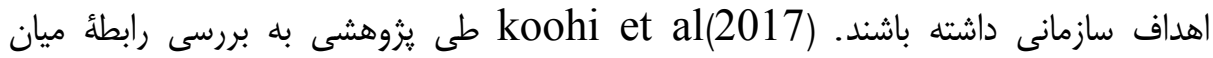

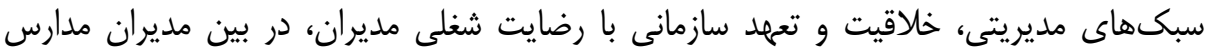

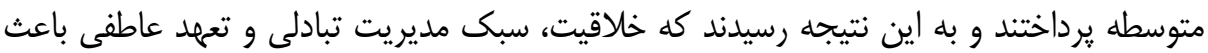

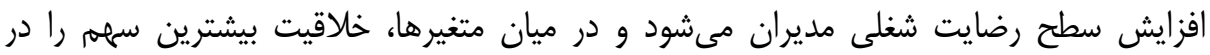


ييشيينى رضايت شغلى دارد. Abili et al(2014) در مطالعالى به بررسى تأثير مديريت

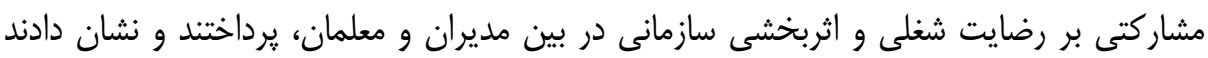

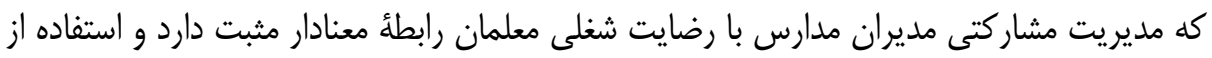

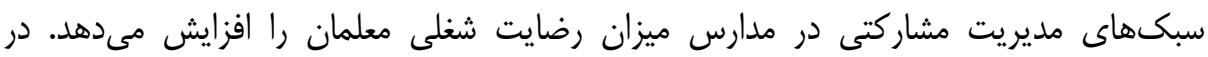

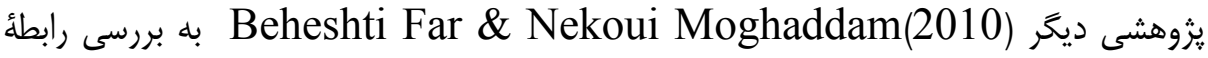

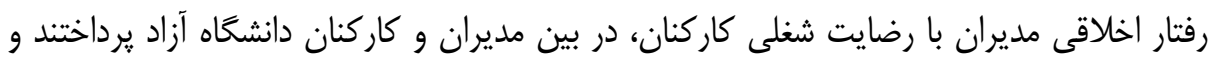

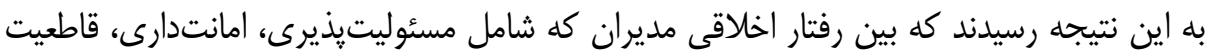

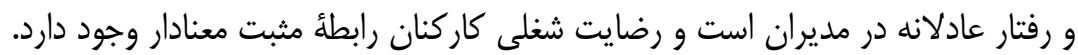

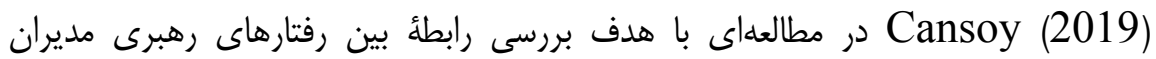

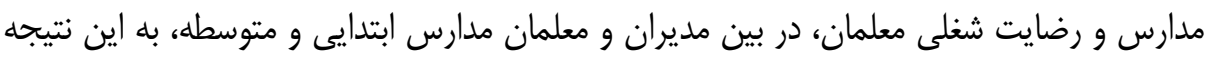

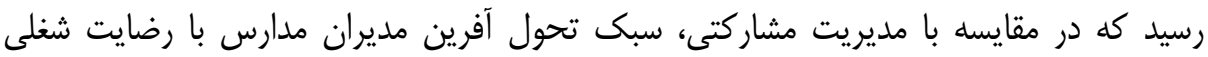

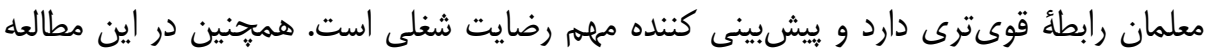

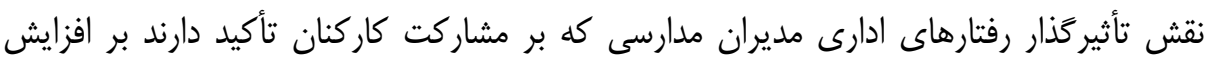

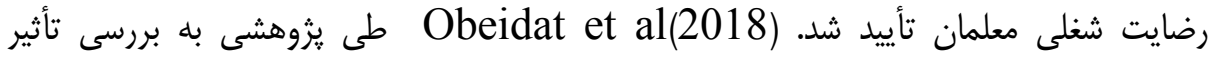

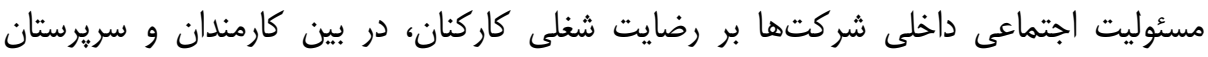

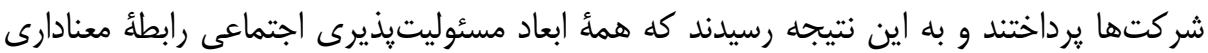

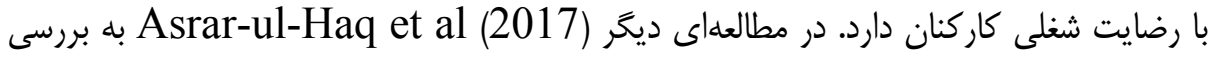

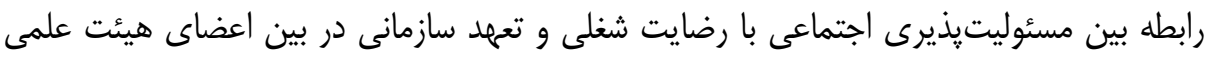

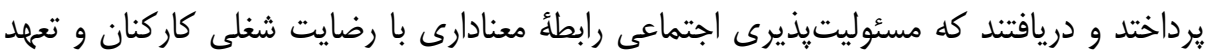

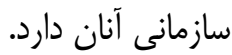

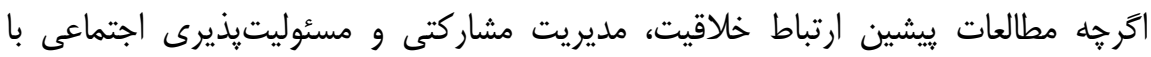

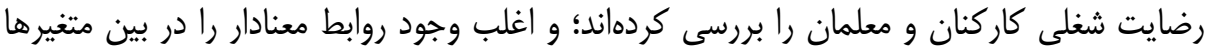

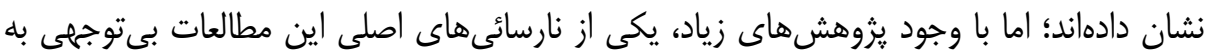

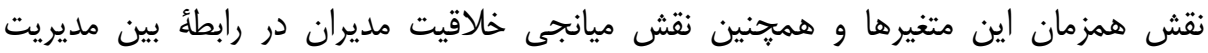

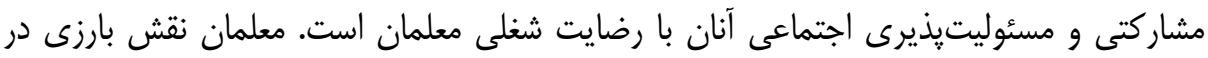

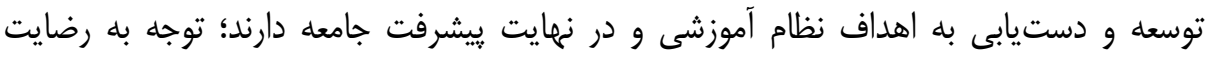

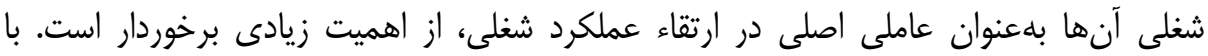


عنايت به تأثير روابط بين مدير و معلم، در افزايش روحيه، نشاط شغلى و درنهايت رضايت شغلى مانى

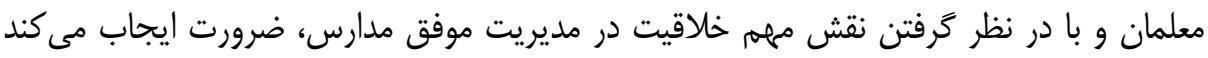

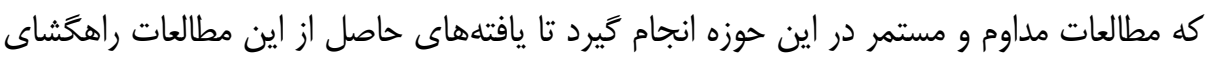

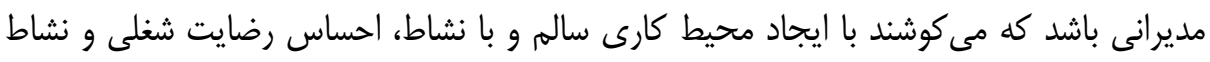

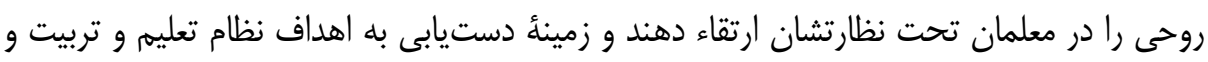

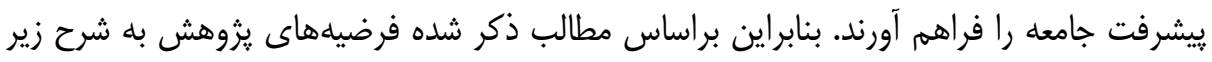
نوشته شد:

1. مديريت مشار كتى مديران بر رضايت شغلى معلمان اثر مستقيم دارد.

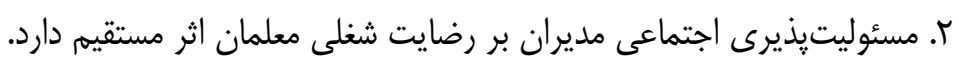
س. خلاقيت مديران بر رضايت شغلى معلمان اثر مستقيم دارد.

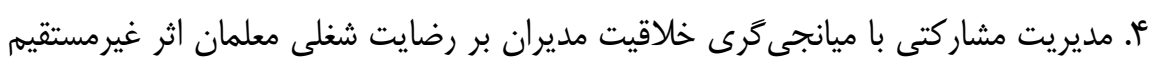
دارد. ه. مسئوليتيذيرى اجتماعى با ميانجى گرى خلاقيت مديران بر رضايت شغلى معلمان اثر

$$
\text { غير مستقيه دارد. }
$$

در اين راستا بر اساس مطالعات يادشده، نتايج يزوهشهاى دان انجام شده و همجنين فرضيههاى يخوهش، مدل مفهومى يزوهش به صورت شكل شماره ا تدوين خرديد. 


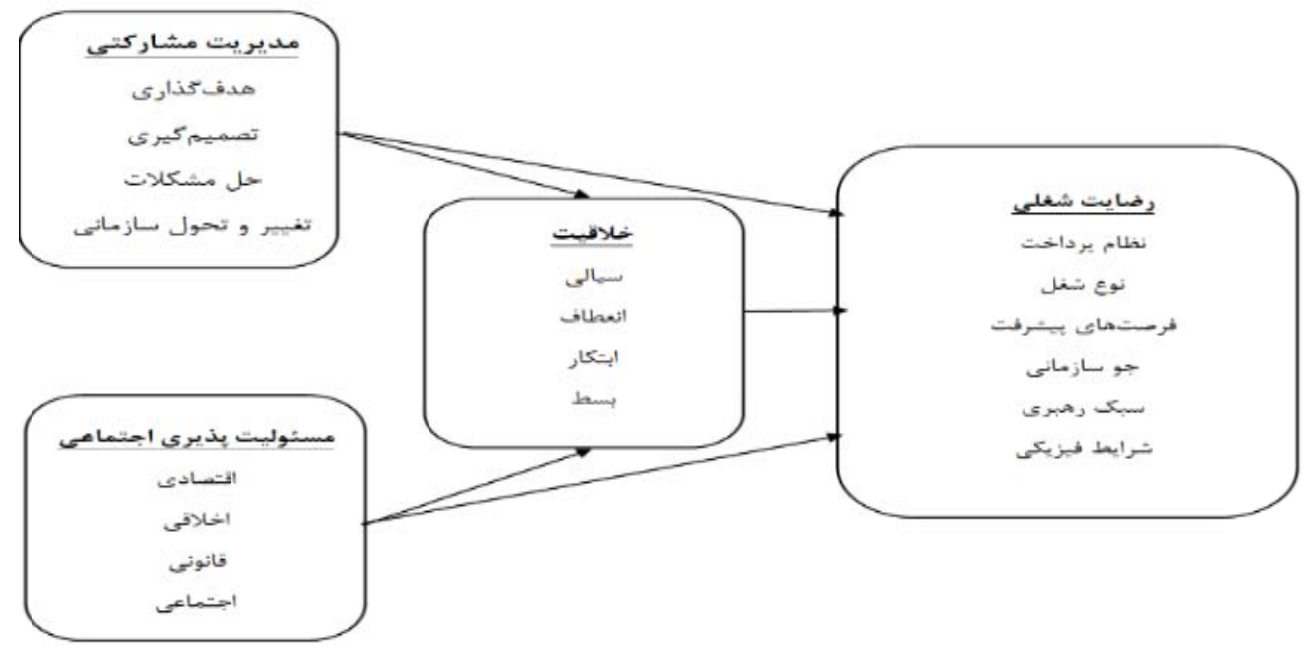

شكل (. مدل مفهومى يزوهش

\section{روش شناسى يزوهش}

بر اساس هدف و ماهيت موضوع، روش يثوهش از لحاظ رويكرد كمّى و از حيث هدف كاربردى و وإس

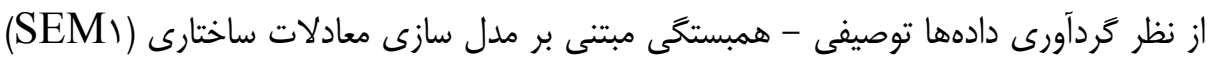

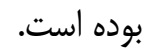

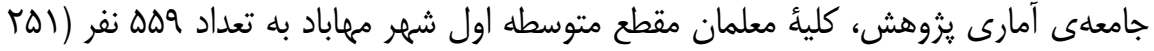

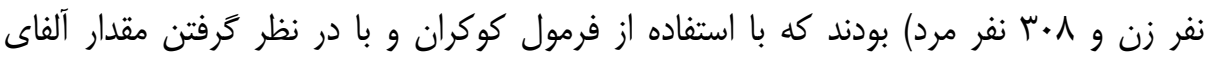

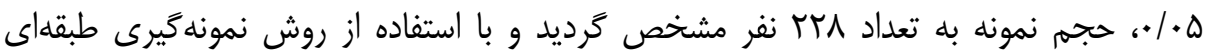

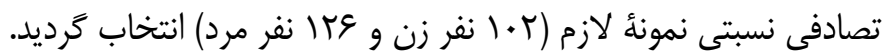

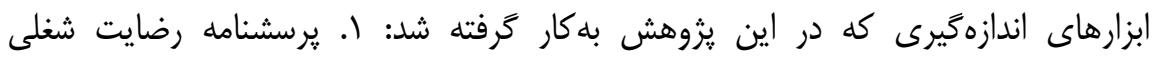

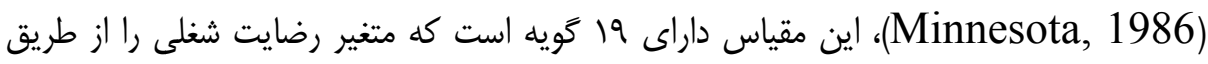

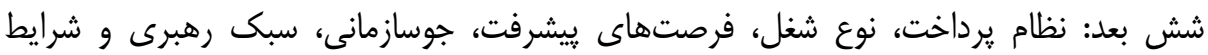

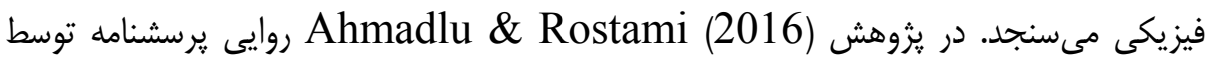

1. structural equation modeling 
اساتيد علوم تربيتى تأييد شده و آلفاى كرونباخ آن بر/ • بهدست آمد. در يزوهش حاضر روايى

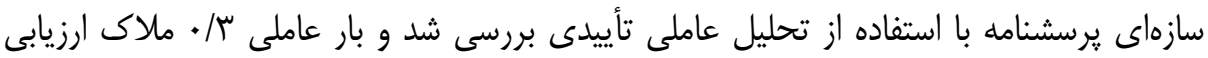

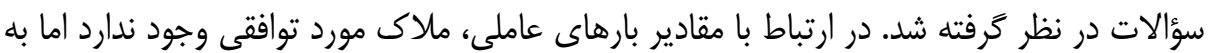

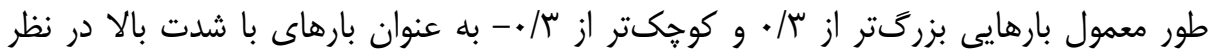

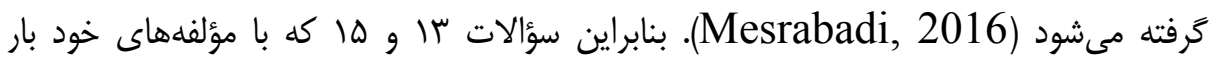

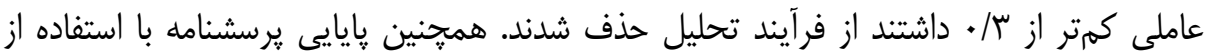

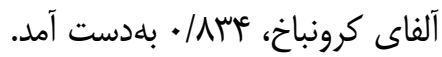

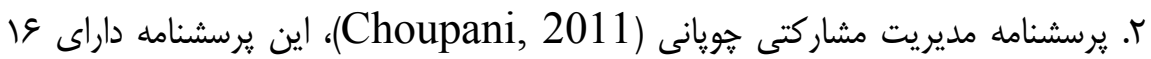

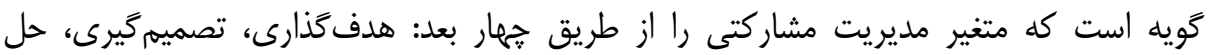

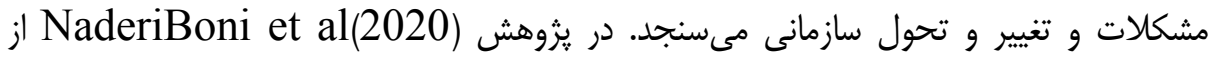

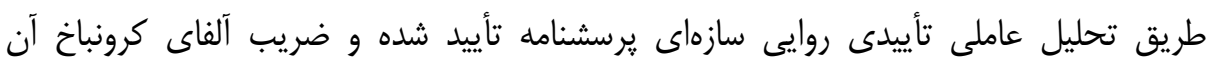

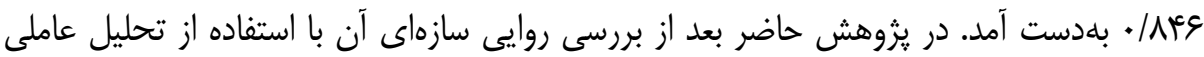

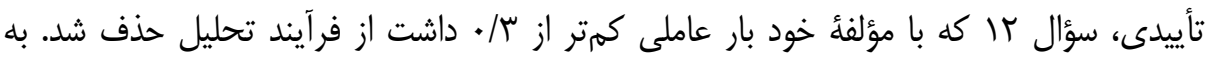

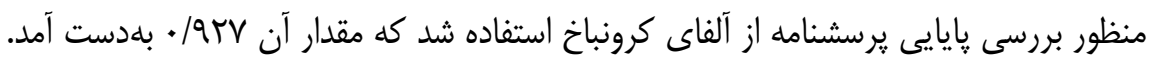

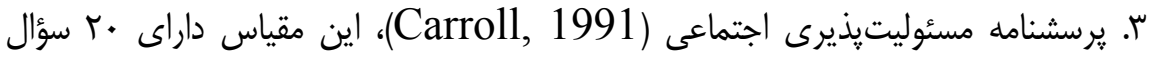

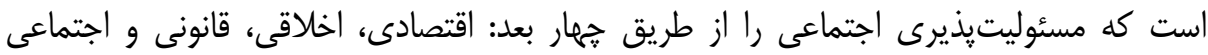

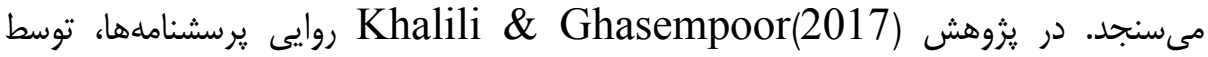

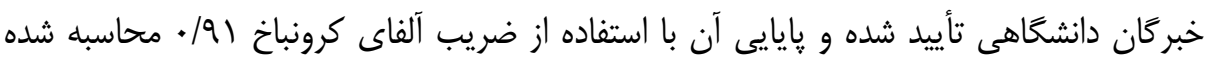

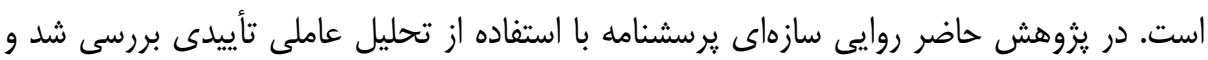

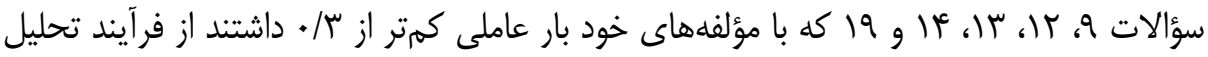

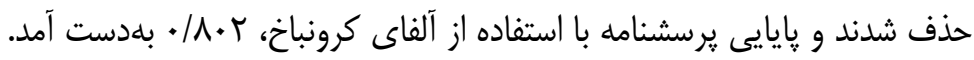

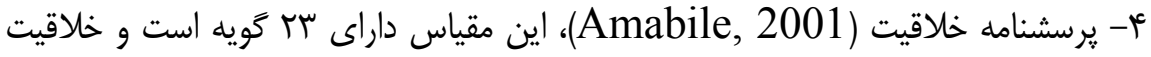

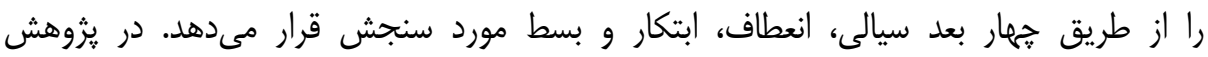

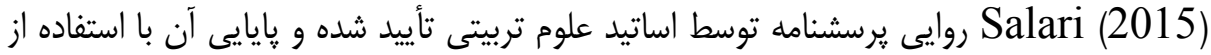

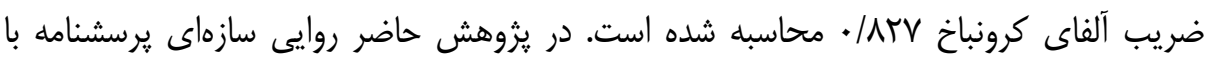

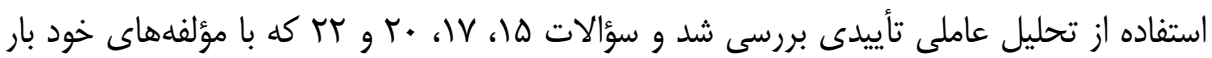


نقش مديريت مشاركتى و .... زوار، بهارى، عبدالهى اصل، دلخوش

عاملى كمتر از س/ء داشتند از فرايند تحليل حذف شدند. همجنين به منظور بررسى پايايى

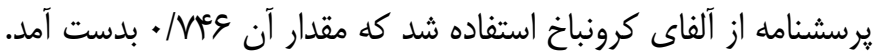

جدول (: شاخصهاى مدل تحليل عاملى تأييدى برسشنامهها بعد از اصلاح مدلها

\begin{tabular}{|c|c|c|c|c|c|c|c|c|}
\hline $\begin{array}{c}\mathrm{p}- \\
\text { value }\end{array}$ & PCFI & IFI & CFI & RMSEA & $\begin{array}{r}\text { CMIN } \\
/ \mathrm{DF}\end{array}$ & $\mathrm{DF}$ & CMIN & \\
\hline.$/ . .1$ &. & س & ./991 & $.1 . \varphi_{\Delta}$ & $1 / 499$ & $11 r$ & $|G F /| Q \mid$ & رضايت شغلى \\
\hline. $\mid . .1$ &.$/ v \Delta$. &.$/ 9.9$ &.$/ 9.9$ & 1.45 & $r / 19$ & n & $1.1 / A \vee G$ & مديريت مشار كتى \\
\hline. $\mid . .1$ & $\cdot / v \cdot 1$ &.$/ 9 \Delta \Delta$ &.$/ 9 \Delta f$ & .1 .49 & $1 / \Lambda / r$ & 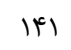 & r.N/TFT & مسئوليت اجتماعى \\
\hline.$/ . r$ &.$/ 999$ &.$/ 9 \Delta$. & . /9g4 &.$/ . r q$ & I & Mr & IFT/THI & خلاقيت \\
\hline كمتر & بيشتر & بيشتر & بيشتر & كمتر از هـ/. & بين ا تا ه & & & مطلوب \\
\hline .1 .0 & $\mid$ & | & | & & & & & شاخص \\
\hline
\end{tabular}

جدول (1) نشان دهندهى شاخصهاى برازش مدل تحليل عاملى تأييدى يرسشنامهها بعد از

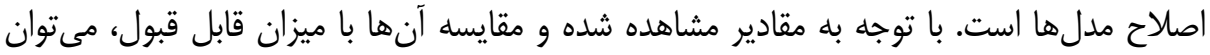

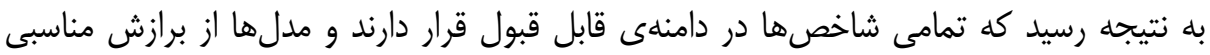

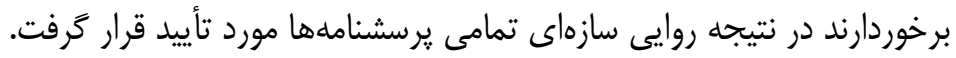

\section{يافتههاى يزوهش}

در اين بخش از يزوهش دادههاى جمعآورى شده براى بررسى آمارههاى توصيفى، آزمون مدل يزوهش و فرضيههاى يخوهش با استفاده از نرم افزار

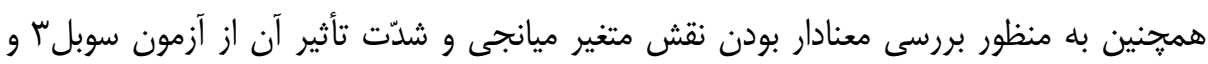
VAFץ

1. statistical package for social science

2. analysis of moment structures

3. sobel test

4. variance accounted for 
هديريت بر آهوزش سازمانها

\section{جدول r: توزيع دموَّر افيك نمونة مورد مطالعه}

\begin{tabular}{|c|c|c|c|c|}
\hline ميانگين & درصد فراوانى & فراوانى & & \\
\hline & $F+/ V$ & $1 . r$ & زن & جنسيت \\
\hline & $\Delta \omega / \Gamma$ & E & مرد & \\
\hline & $r M / l$ & iᄉ & זr تا سץ سال & \\
\hline \multirow[t]{6}{*}{ rq/Tr } & $\Delta T / \varepsilon$ & ir. & عب تا ع ب سال & سن \\
\hline & س & q. & هأ تا هه سال & \\
\hline & $\Gamma / \Delta$ & $\wedge$ & فوق دييلم & \multirow{3}{*}{ تحصيلات } \\
\hline & $\Delta N / \Lambda$ & IMF & ليسانس & \\
\hline & $\mathrm{rV} / \mathrm{V}$ & $\wedge \varepsilon$ & فوق ليسانس و بالاتر & \\
\hline & $M F / r$ & VA & ا تا •ا سال & \multirow{3}{*}{ سابقه خدمت } \\
\hline \multirow[t]{2}{*}{$\mid \Delta / \& 9$} & اع & או & Iا تا •r سال & \\
\hline & $r q / 4$ & qV & آ تا •r سال & \\
\hline
\end{tabular}

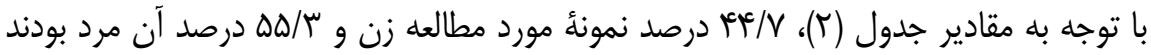
كه ميانگين سنى و سابقهى خدمت آنها به ترتيب برابر r//وس سال و و\&/ها سال بود. همجنين در ارتباط با سطح تحصيلات شركت كنندگان در يزوهش، گروه ليسانس با هN/N درصد بيشترين فراوانى و گروه فوق دييلم با ه/س درصد كمترين درصد فراوانى را داشتند.

جدول سا: ميانتين، انحراف معيار، آزمون شاييرو - ويلك و همبستكى ميان متغير هاى يزوهش ازئ سياريرو

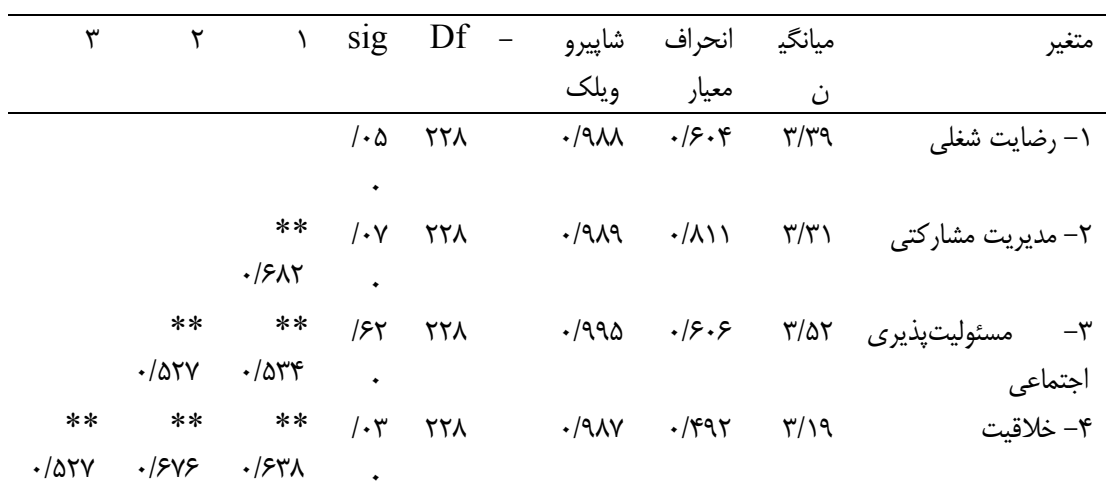

* * معنى دارى در سطح 1.|. 
در جدول (ب) نتايج نشان مىدهد كه ميانگين همأ متغيرها در سطح بالاتر از متوسط (عدد بـ

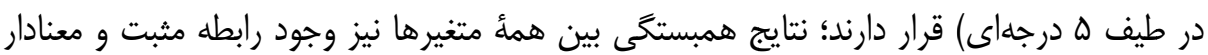

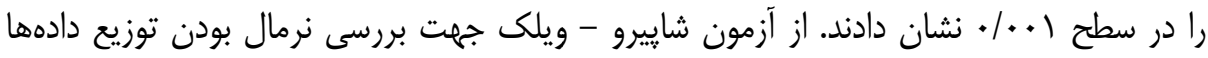

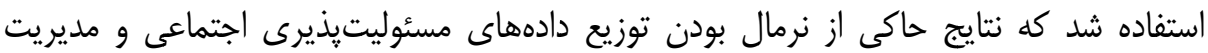

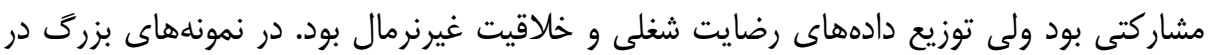

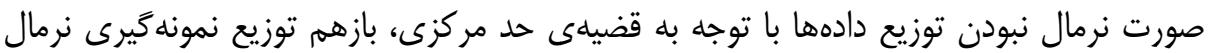

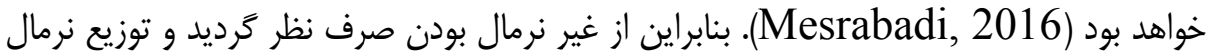
فرض شد. در ادامه، الكوى مفهومى يثوهش با روش مدليابى معادلات ساختارى به روش تحليل مسير

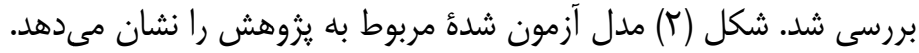

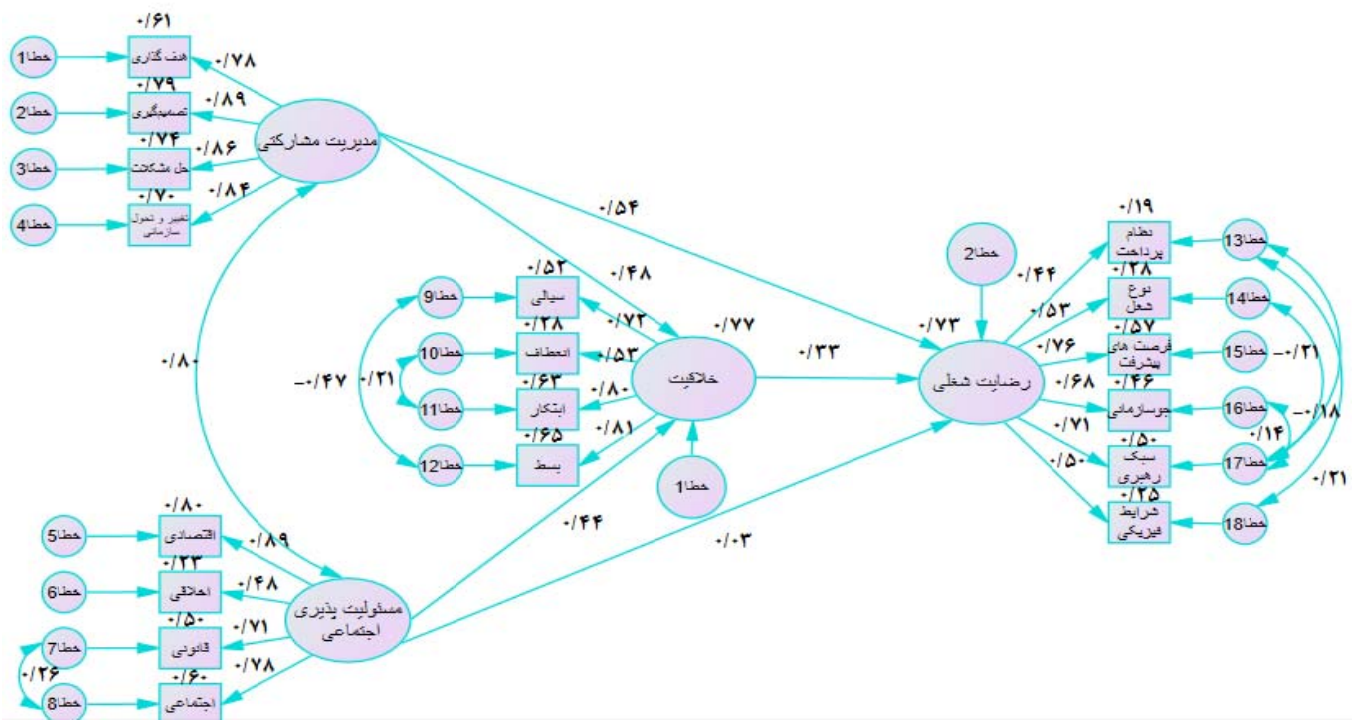

شكل r. مدل آزمون شده يزوهش 
به منظور بررسى برازش مدل يُوهش از شاخصهاى برازش استفاده شد. مقادير اين

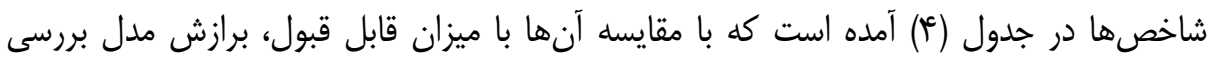
كرديد.

جدول ع: شاخصهاى برازش مدل آزمون شدهٔ يزوهش

\begin{tabular}{|c|c|c|c|c|c|c|c|c|c|}
\hline $\begin{array}{r}p- \\
\text { value }\end{array}$ & PCFI & IFI & CFI & NFI & RMSEA & $\begin{array}{r}\text { CMIN } \\
/ \text { DF }\end{array}$ & $\overline{D F}$ & CMIN & نام آزمون \\
\hline.$/ .1$ & . $/ \mathrm{VA}$ & . /9TD & . /quF & - /MA & $.1 \cdot v 1$ & $r / I F$. & irs & $r V r / q \cdot e^{c}$ & مقادير قبل از \\
\hline.$/ . .1$ & . IVYG & . &.$/ 991$ &.$/ 91 \%$ &.$/ \Delta F$ & $1 / v \cdot 1$ & $1 \pi T$ & $r \cdot N / T T F$ & مقادير بعد از مدل \\
\hline
\end{tabular}

با توجه به مقادير بعد از اصلاح مدل در جدول (أ) مىتوان نتيجه گرفت كه دادههاى تجربى

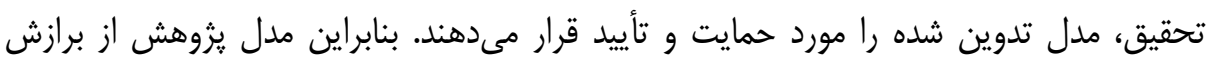

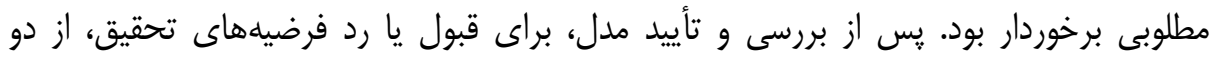

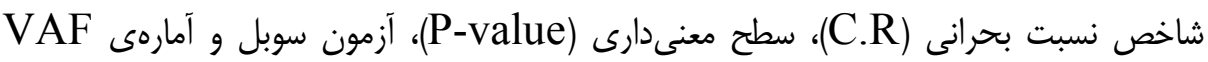

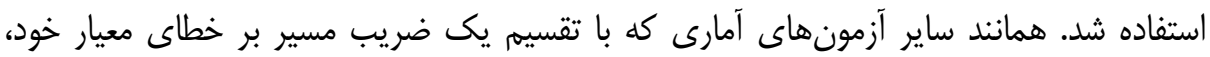

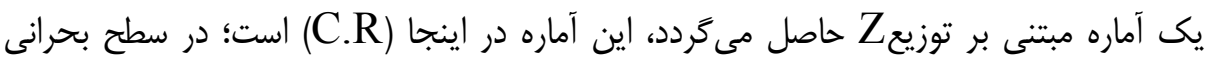

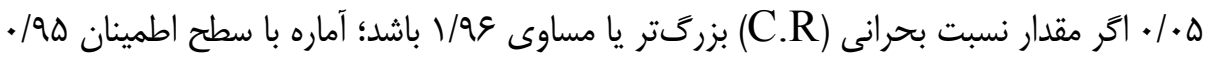
معنى دار تلقى مى گردد (Mesrabadi, 2016).

\begin{tabular}{|c|c|c|c|c|c|c|}
\hline P-value & C.R. & S.E. & Estimate & & & \\
\hline.$/ \cdot 1$ & $r / q .$. & .1 .94 & rir & خلاقيت & $\leftarrow$ & مديريت مشار كتى \\
\hline $.1 . .1$ & $\varphi / \Delta \Delta$. &.$/ . \wedge V$ & ./rqv & خلاقيت & $\leftarrow$ & مسئوليتيذيرى اجتماعى \\
\hline ./Arr &.$/ 4 \cdot 9$ & .1 .09 & .1 .11 & رضايت شغلى & $\leftarrow$ & مسئوليتيذيرى اجتماعى \\
\hline.$/ . .1$ & $r / 9 / r$ & $.1 .+\mathrm{V}$ &.$/|v|$ & رضايت شغلى & $\leftarrow$ & مديريت مشار كتى \\
\hline.$/ .4 \mathrm{~V}$ & $r / \cdot \Lambda 1$ & $\cdot / \cdot V V$ &.$/ 19$. & رضايت شغلى & $\leftarrow$ & خلاقيت \\
\hline
\end{tabular}


همانطور كه در جدول (ه) نشان داده شده، نسبت بحرانى (C.R) تمامى مسيرهاى موجود در

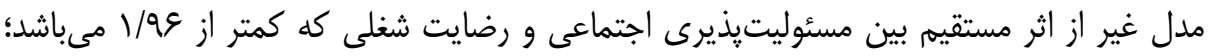

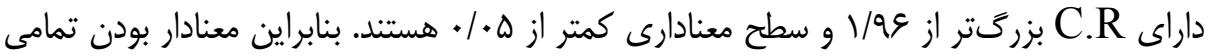
مسيرها غير از اثر مستقيم مسئوليتيذيرى اجتماعى بر رضايت شغلى تأييد شد.

جدول 7: نتايج بررسى فرضيههاى مربوط به اثرات مستقيم

\begin{tabular}{|c|c|c|c|c|}
\hline نتيجه & P-valu & (C.R) & ضريب استاندارد & فرضيه \\
\hline تأييد & $.1+.1$ & r/gIr & $\cdot / \Delta F$ & معلمان اثر مستقيم دارد. مشيران مدان بر رضايت شغلى \\
\hline رد & . / & $\cdot / r \cdot 9$ &.$/ . r$ & شغئوليتيذيرى اجتماعى مديران بر رضايت \\
\hline تأسد & . & $r / \cdot \Lambda I$ & سז/. & خلاقيت مديران بر رضايت شغلى معلمان اثر \\
\hline
\end{tabular}

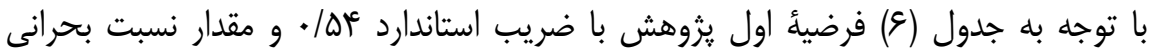
(C.R)

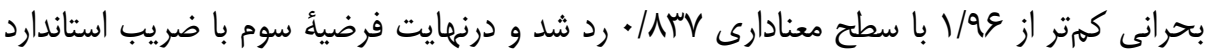

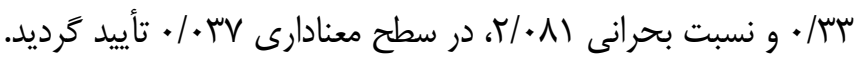

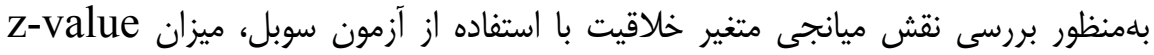

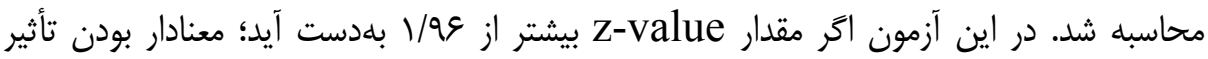
متغير ميانجى در سطح اطمينان هو/ • تأييد مى درود.

$$
\mathrm{z}-\mathrm{value}=\sqrt{\frac{\mathrm{a} * \mathrm{~b}}{\left(\mathrm{~b}^{2} * \mathrm{~s}^{2}{ }_{\mathrm{a}}\right)+\left(\mathrm{a}^{2} * \mathrm{~s}_{\mathrm{b}}\right)+\left(\mathrm{s}_{\mathrm{a}}{ }^{2} * \mathrm{~s}_{\mathrm{b}}\right)}}
$$


در فرمول بالا، a برابر ضريب مسير بين متغير مستقل و ميانجى و b برابر ضريب مسير بين

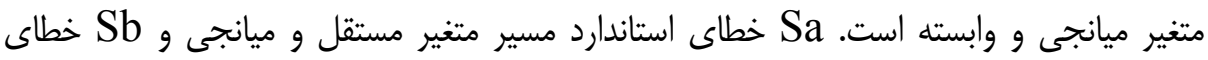
استاندارد مسير متغير ميانجى و وابسته مىباشد.

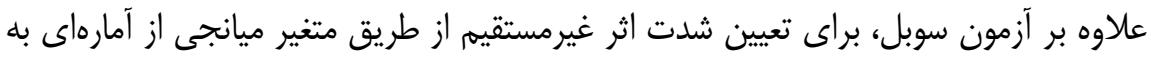

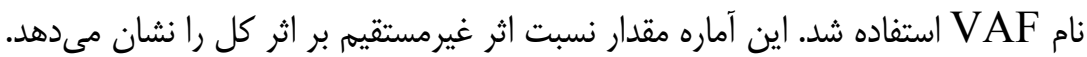

$$
\mathrm{VAF}=\frac{\mathrm{a} * \mathrm{~b}}{(\mathrm{a} * \mathrm{~b})+\mathrm{c}}
$$

در فرمول بالا، a برابر ضريب مسير متغير مستقل و ميانجى، b برابر ضريب مسير متغير

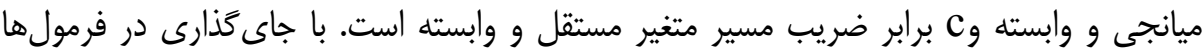

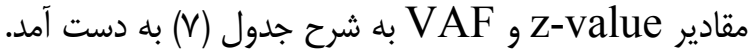

\section{جدول \: نتايج آزمون سوبل و VAF جهت بررسى نقش متغير ميانجى در فرضيهها}

\begin{tabular}{|c|c|c|c|c|}
\hline نتيجه & VAF & سطح|طمينان & z-value & فرضيه \\
\hline تأييد & E &.$/ 90$ & $r / v$. & رضايت شغلى معلمان اثر غيرمستقيم داريت دارد. \\
\hline تأييد & $\cdot / A T A$ &.$/ 90$ & $T / M F$ & 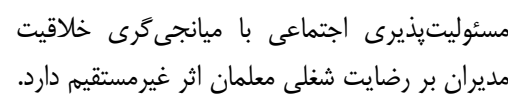 \\
\hline
\end{tabular}

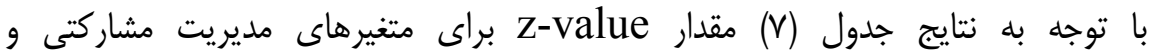

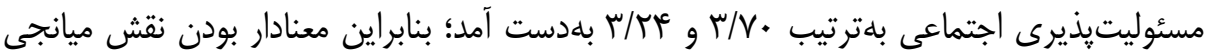

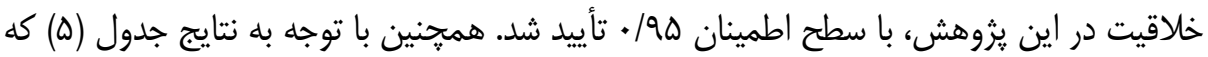

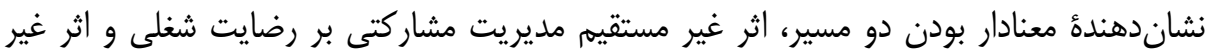

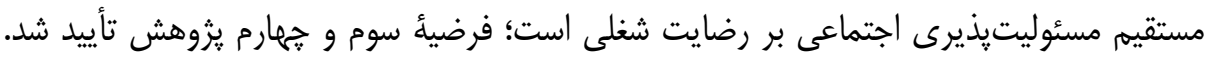

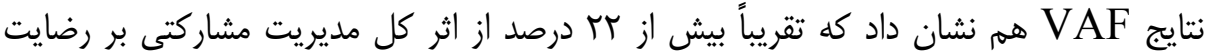

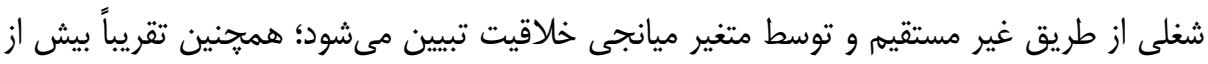


r N درصد از اثر كل مسئوليتيذيرى اجتماعى بر رضايت شغلى از طريق غير مستقيم و توسط متغير ميانجى خلاقيت تبيين مىشود.

\section{بحث و نتيجه}

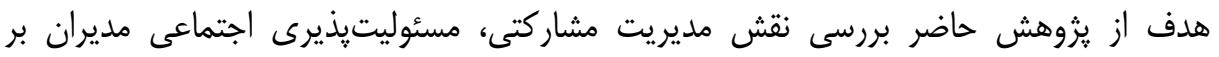

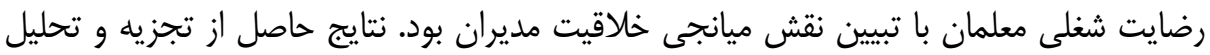

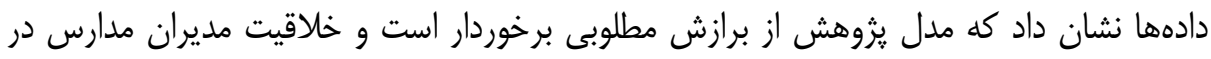

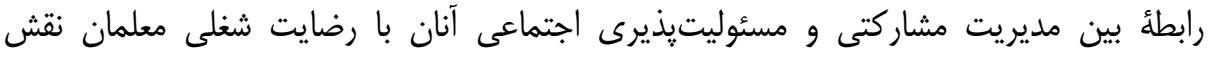

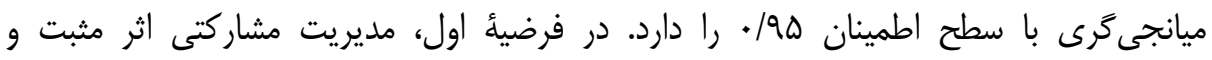

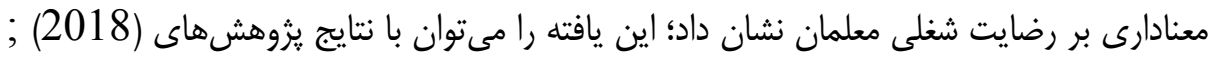
كه در مطالعة خود به اين Abili et al (2014); Crisci et al (2019)Hee et al

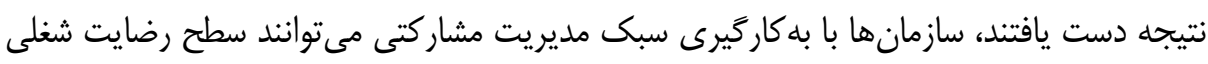

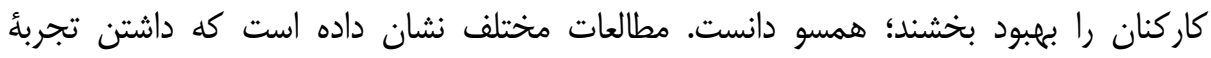

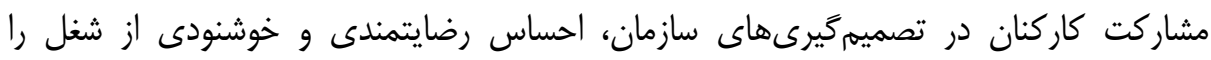

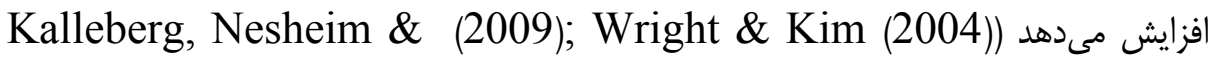
Olsen

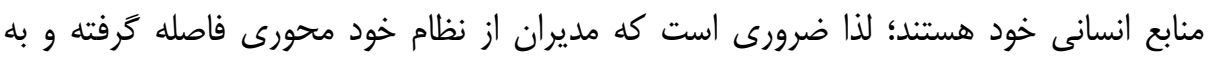

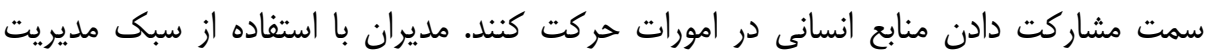

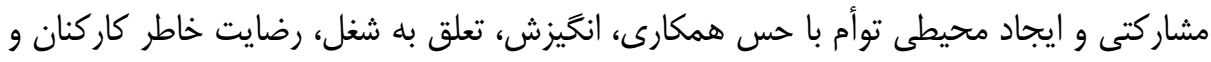

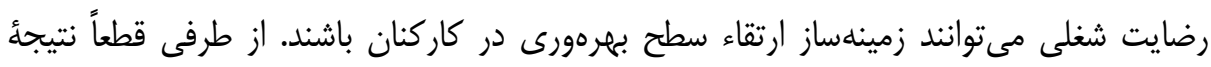

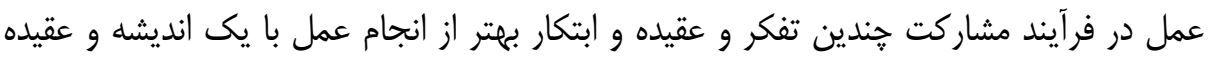

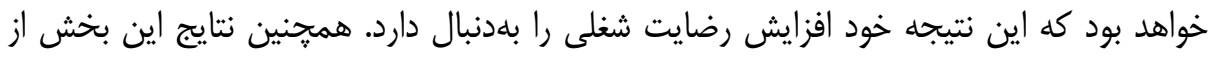

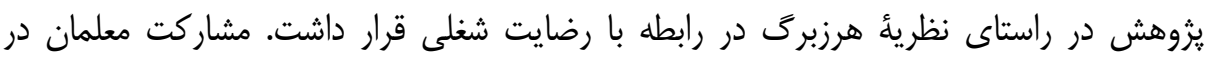

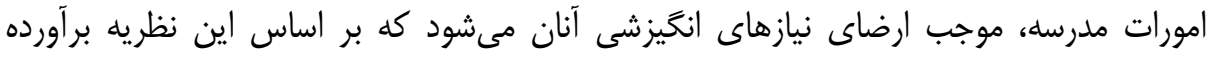

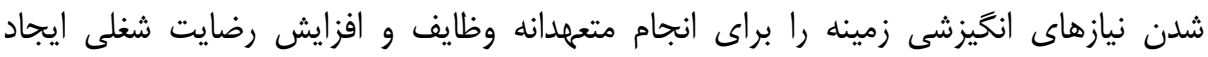

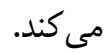


در ارتباط با فرضئ دوم نتايج تجزيه و تحليل دادهها نشان داد كه مسئوليتيذيرى اجتماعى دائي

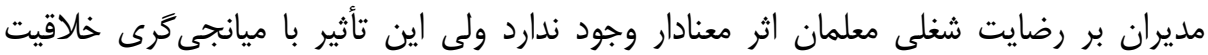

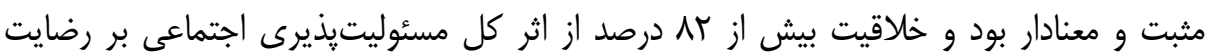

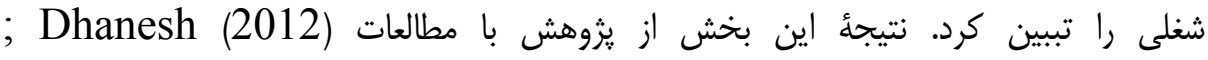

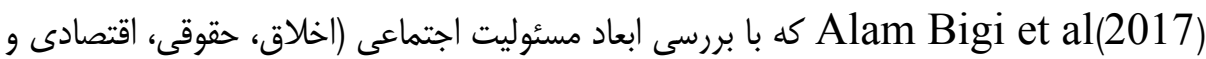

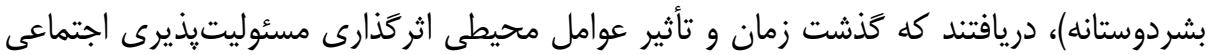

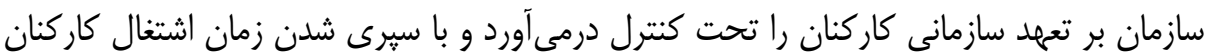

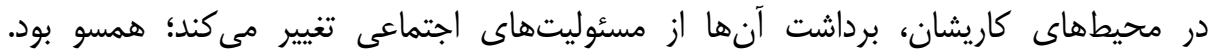

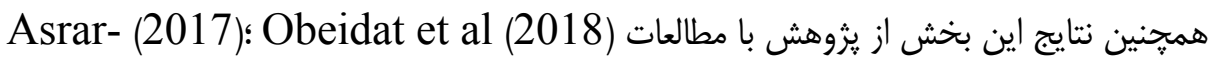

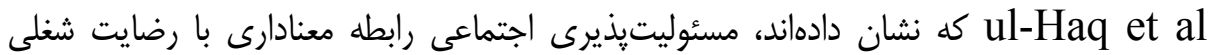
دارد؛ ناهمسو مىباشد.

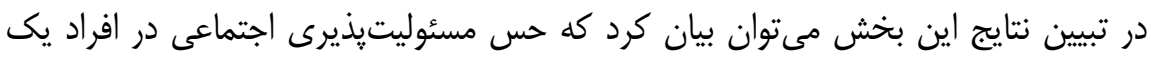

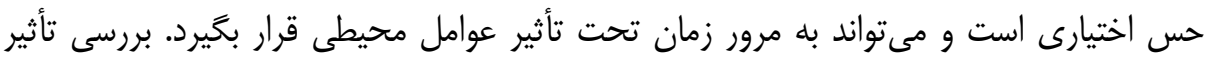

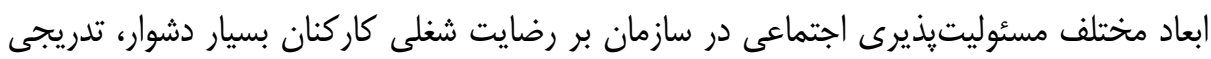

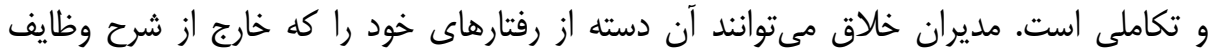

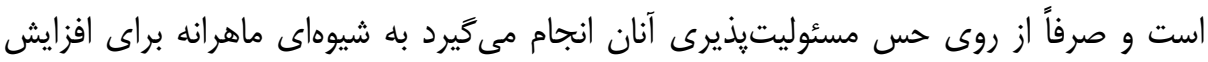

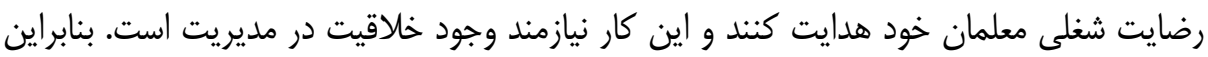

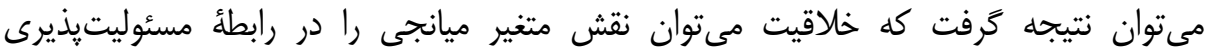
اجتماعى و رضايت شغلى داشته باشد.

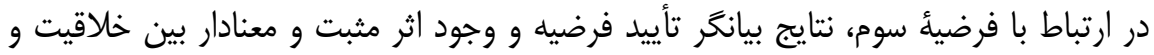

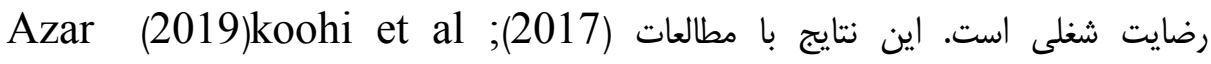
nioushan, Mashayekh, \& Mohammadi Shir mahaleh مطالعات مذكور يروهشكَران به اين نتيجه دست يافتند كه جهت ارتقاى رضايت شغلى و عملكرد

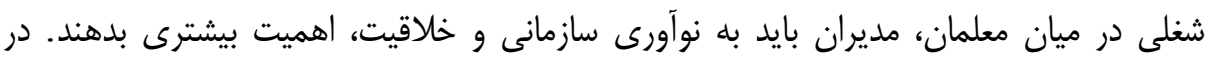

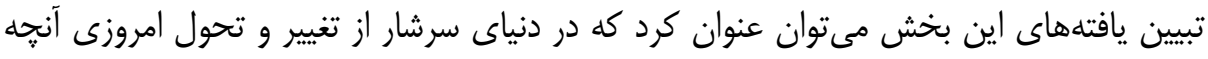

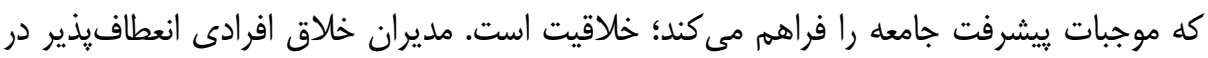

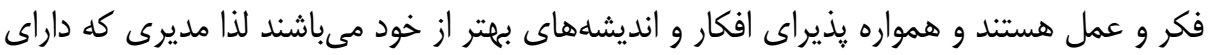


خلاقيت است اين توانايى را دارد كه با ارتقاى كيفيت و كمّيت خدمات و به كاركيرى رفتارهاى

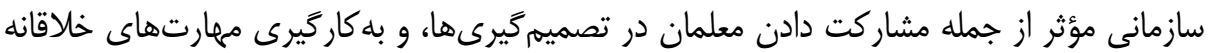

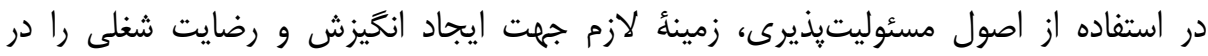

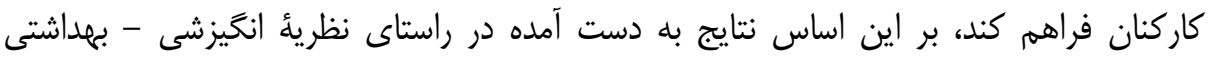

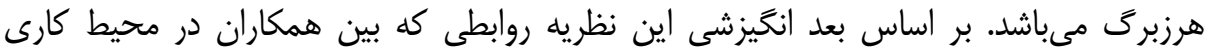
وجود دارد بر روى رضايت شغلى آنان تأثير دارد.

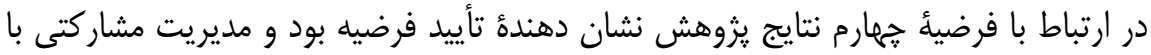

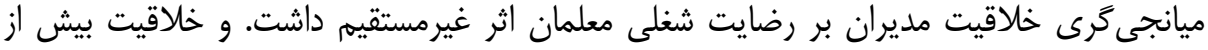

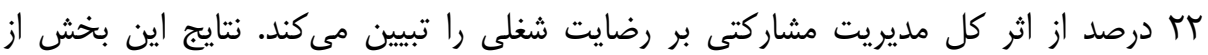

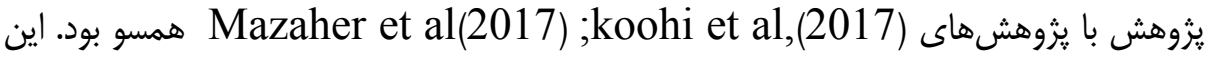

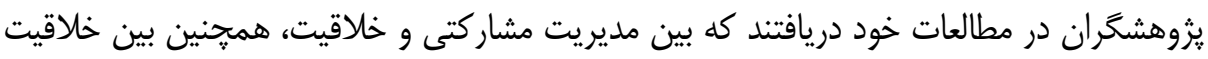

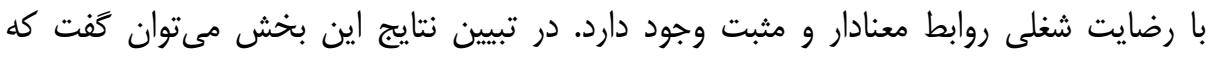

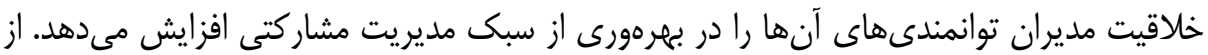

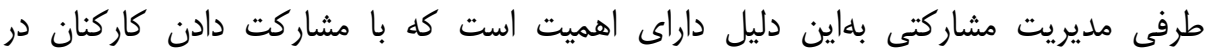

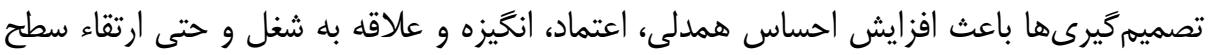

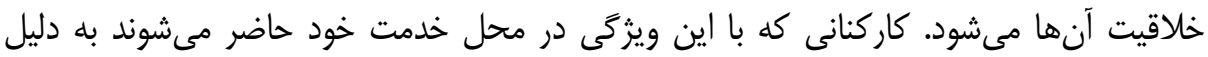

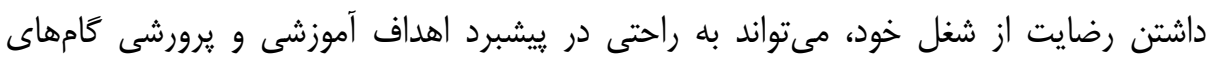
مؤثرى بردارند.

در ارتباط با فرضية ينجم نتايج يزوهش نشان دهندة تأييد فرضيه بود و مسئوليتيذيرى

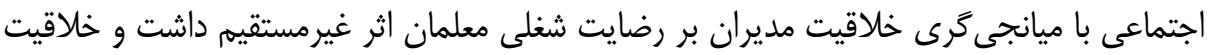

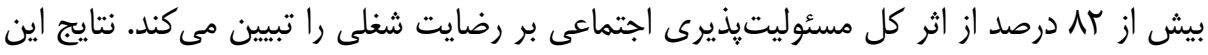

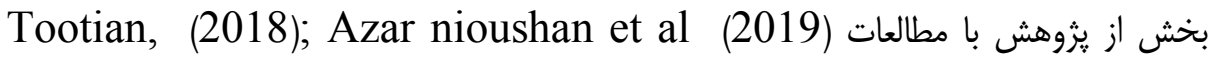
Dehghani Soltani et al (2019); Mehrara \& Bigdeli يزوهشگران در مطالعات خود دريافتند كه بين مسئوليتيذيرى اجتماعى و خلاقيت، همجنين بين

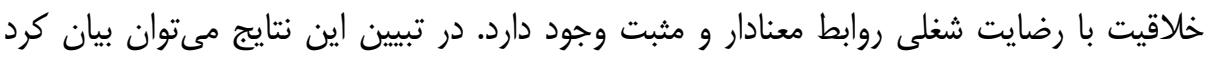

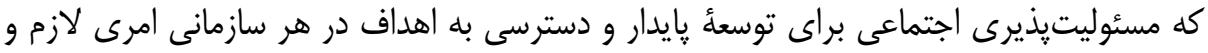

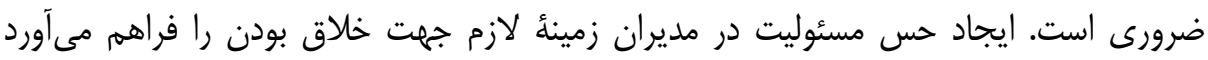


همجنين خلاقيت با افزايش كيفيت و كمّيت خدمات و به كارگيرى سبكهاى تعاملى مؤثر توسط

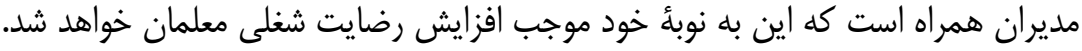

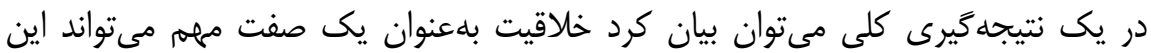

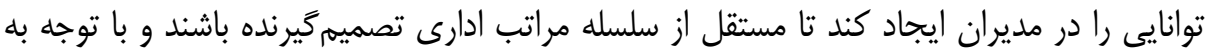

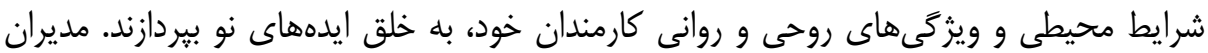

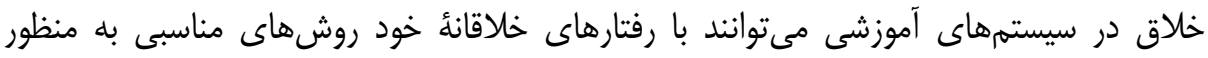

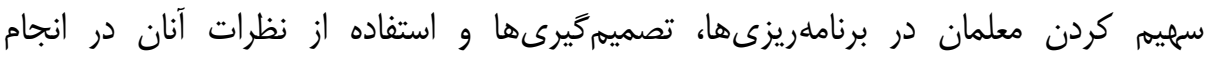

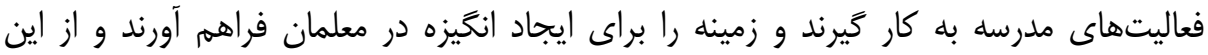

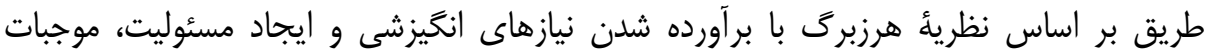

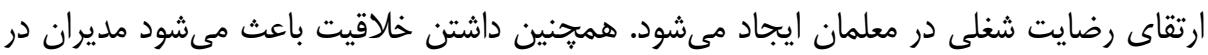

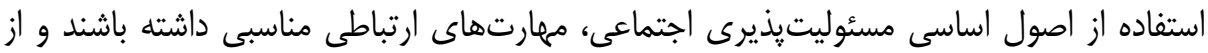

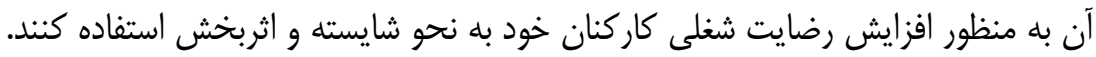

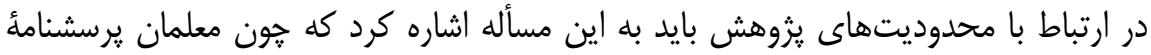

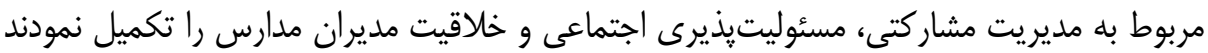

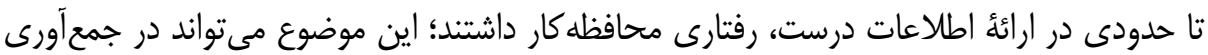

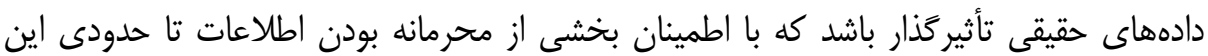

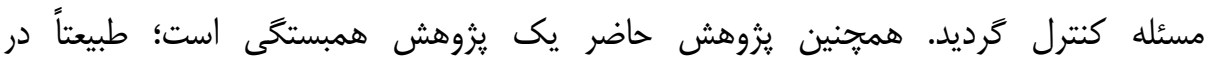

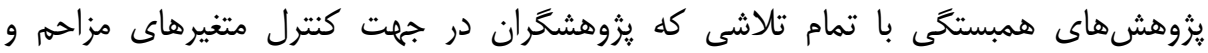

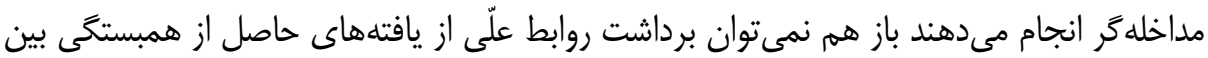

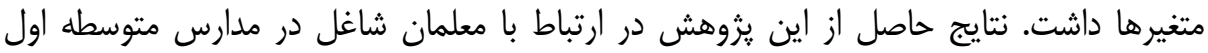

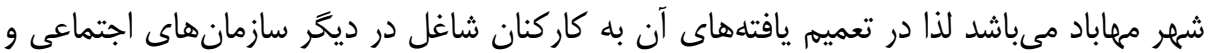
خدماتى لازم است جوانب احتياط رعايت شود.

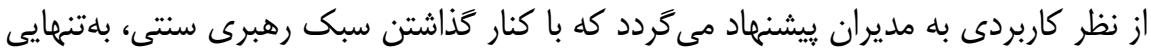

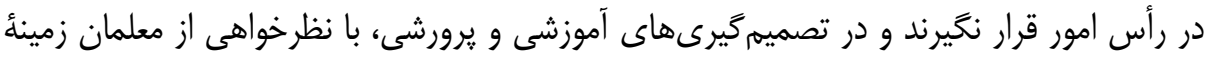

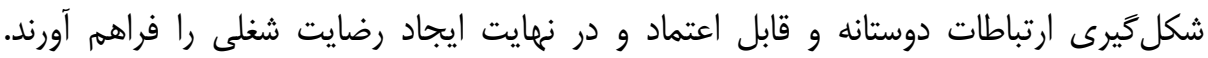

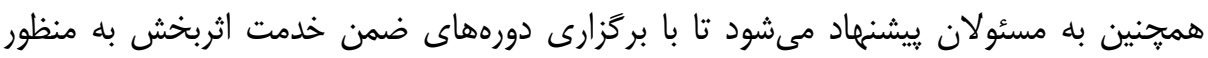

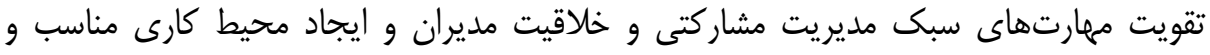


تعاملى بين مديران و معلمان در مدارس، زمينهُ لازم را براى افزايش رضايت شغلى معلمان فراهم

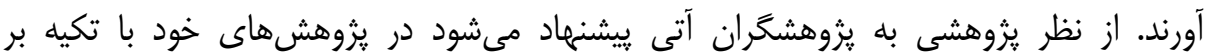

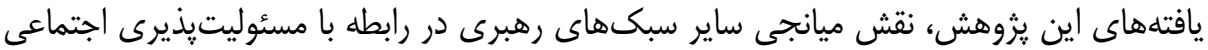

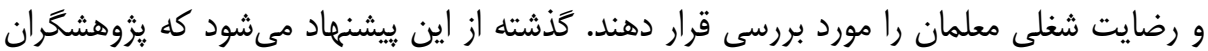

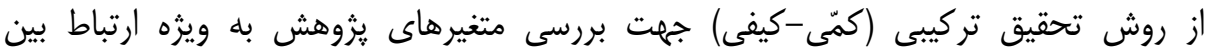

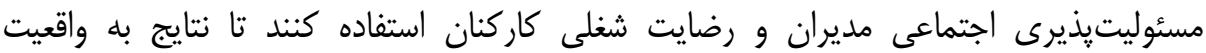

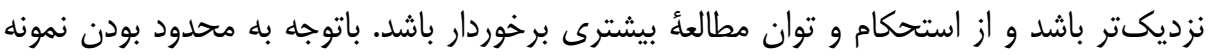
در يزوهش حاضر ييشنهاد مى گردد اين يزوهش در نمونههاى وسيع و جوامع متنوعتر بررسى شود.

\section{تعارض منافع/حمايت مالى}

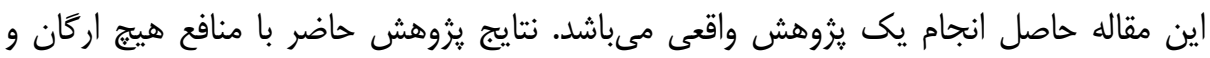
سازمانى در تعارض نيست و بدون حمايت مالى انجام شده است.

\section{منابع}

1. Abedinya, A. (2020). Relationship between leadership styles of educational and training leaders with job satisfaction of multigrade primary school teachers in Talesh city. Applied Educational Leadership, 1(1), 29-42. [in Persian]

2. Abili, K. Naderi, A. Yazdani, B. \& Nastiezaie, N. (2014). "The impact of particip atory management on job satisfa ction and organizat ional effectiveness". The Journal of Urmia Nursing and Midwifery Faculty, 12 (2): 101-108. [in Persian]

3. Ahmadlu, M., \& Rostami, S. (2016). Comparing of teacher's job satisfaction based on principal's educational power bases in primary schools of Tabriz district 4 in the school year 94-95. The Journal of Modern Thoughts in Education, 11(4), 104-191. [in Persian]

4. Akbari, M., Amirmahmoudi, N. (2016). Social Relationship with Job Satisfaction within Governmental Organizations of Bandar Abbas City. Quarterly Journal of Social Development (Previously Human Development), 10 (4), 149-170. [in Persian]

5. Akbari, M., Azar, A., Haji Mahmoudloo, A. \& Aletaha, S. (2020). The Effect of Corporate Social Responsibility on Organizational Citizenship Behavior: Mediating Roles of Occupational Involvement, Job Satisfaction, 
and Employees Voice. Journal of Human Resource Management, 9(4), 124. [in Persian]

6. Alam Bigi, A. Batthai, S., S. Rezvanfar, A. \& Afghahi, B. (2017). "Predicting Job Commitment Based on Organizational Social Responsibility with Predictive Segmentation Algorithm". Organizational Resource Management Research, 7 (1), 169-188. [in Persian]

7. Asrar-ul-Haq, M. Kuchinke, K. P. \& Iqbal, A. (2017). "The relationship between corporate social responsibility, job satisfaction, and organizational commitment: Case of Pakistani higher education". Cleaner Production, $142,2352-2363$.

8. Azar nioushan, M. Mashayekh, M. \& Mohammadi Shir mahaleh, F. (2019). "The relationship between teachers' organizational innovation and job performance and job satisfaction". Innovation and Creativity in Human Sciences, 8 (3), 75-94. [in Persian]

9. Beheshti Far, M. \& Nekoui Moghaddam, M. (2010). "The Relationship between Managers 'Ethical Behavior and Employees' Job Satisfaction". Ethics in Science and Technology Quarterly, 5 (1\&2), 67-74. [in Persian]

10. Brezicha, K. F., Ikoma, S., Park, H., \& LeTendre, G. K. (2020). The ownership perception gap: Exploring teacher job satisfaction and its relationship to teachers' and principals' perception of decision-making opportunities. International Journal of Leadership in Education, 23(4), 428-456

11. Bucur, I. (2013). Managerial core competencies as predictors of managerial performance, on different levels of management. Procediasocial and behavioral sciences, 78, 365-369.

12. Cansoy, R. (2019). "The Relationship between School Principals' Leadership Behaviours and Teachers' Job Satisfaction: A Systematic Review". International Education Studies, 12(1), 37-52.

13. Crisci, A., Sepe, E., \& Malafronte, P. (2019). "What influences teachers' job satisfaction and how to improve, develop and reorganize the school activities associated with them". Quality \& Quantity, 53 (5), 2403-2419.

14. Dehghani Soltani, M., Mesbahi, M. \& Hoseinkhani Naniz, M. (2019). The Effect of Psychological Capital and Social Responsibility on Emotional Organizational Commitment and Creativity of Employees. Human Resource Management in Oil Industry, 11(41), 95-128. [in Persian]

15. Dhanesh, G. S. (2012). "The view from within: Internal publics and CSR". Communication Management, 16(1), 39-58.

16. Fakharian, J. Shahamat, N. \& Amirian, Z. (2015). "The relationship between participatory management style and organizational commitment and mental health of high school teachers". Journal of New approaches in educational administration, 15(1), 221-234. [in Persian] 


$$
\text { نقش مديريت مشاركتى و .... زوار، بهارى، عبدالهى اصل، دلخوش }
$$

17. Gultekin, O. (2019). "Social Capital's Effect on Physical Education and Teachers' Job Satisfaction". Journal of Education and Learning, 8(1), 164171.

18. Hee, O., C. Yan, L., H. Rizal, A., M. Kowang, T., O. \& Fei, G., C. (2018). "Factors Influencing Employee Job Satisfaction: A Conceptual Analysis". International Journal of Academic Research in Business and Social Sciences, 8(6), 331-340.

19. Kalleberg, A. L. Nesheim, T. \& Olsen, K., M. (2009). "Is Participation Good or Bad for Workers? Effects of Autonomy, Consultation and Teamwork on Stress Among Workers in Norway". Acta Sociologica, 52(2), 99-116.

20. Khalili, K., \& Ghasempoor, H. (2017). Studying the Impact of Corporate Social Responsibility on Job Attitude Employees Health Centers of Ilam. journal of ilam university of medical sciences, 25(4), 90-98. [in Persian]

21. koohi, A. Ahmadi, G. Ashoori, J. \& Beyrami, R. (2017). "The relationship between management styles, creativity and organizational commitment with job satisfaction of managers". Abi-Quarterly Journal of Educational and Scholastic Studies, 6(2), 9-28. [in Persian]

22. Mazaher, L., Mohammadi, S., Ekradi, E., Parvin, E. \& Fazeli, H. (2017). Studying the Relationship between Managers' DecisionMaking Styles with the Level of Creativity and Participative Management in Guidance Schools. Innovation and Creativity in Human Sciences, 6(4), 171-196. [in Persian]

23. Mesrabadi, J. (2016). Pplication of Inferential Statistics in Behevioral Sciences. Tabriz: Azarbaijan Shahid Madani University. [in Persian]

24. Mehri, D. Abolghasemi, M. Mahboub Eshratabadi, H. \& Mahdavi Nik, M. (2014). "Examining the Relationship between Leadership Styles of School Administrators and Teachers Creativity in Elementary Schools of Poldokhtar". Innovation and Creativity in Human Sciences, 3(3), 187-209. [in Persian]

25. Mirkamali, S. Romiani, U. \& Abdolvahabi, M. (2017). "Explainin the role of change management knowledge \& attitudes of Khoram Abad Schools managers in theirs creativity". School Administration, 4(2), 23-44. [in Persian]

26. NaderiBoni, N., Moradyani, L., Bagheri, G. \& Ebrahimi, S. (2020). The effect of managers coaching qualifications on participatory management of Nahavand schools. Jsa, 8 (1), 46-24. [in Persian]

27. Obeidat, D. Yousef, B. Altheeb, S. \& Masa'deh, R., E. (2018). "The Impact of Internal Corporate Social Responsibility on Job Satisfaction in Jordanian Pharmaceutical Companies”. Modern Applied Science, 12(11), 105-120. 
28. Ordoo, F., Arabzadeh, E. (2020). "Investigating the Effective Quality on Organizational Creativity from the Academic Perspective". Strategic Management Studies, 11(41), 1-20. [in Persian]

29. Rowshan, S. \& Farzaneh Hassanzadeh, J. (2014). "The Impact of CSR on Organizational Relationship Quality and Outcomes". Organizational Behaviour Studies Quarterly, 28(3), 109-136. [in Persian]

30. Salari, M. (2015). Studied the relationship between creativity managers and staff Motivation (Department of Education Qeshm). Master thesis in the governmental management. University of Hormozgan. [in Persian]

31. Sepahmansoor, M. Shahriaariahmadi, M. \& Shahaami, N. (2012). Relationship between Life Quality, Job Satisfaction, and Teachers' Professional Exhaustion. Educational Administration Research, 3(11), 91110. [in Persian]

32. Shirbagi, N. \& Mmoradi, O. (2018). Representation of Teachers' Experience From Inappropriate Interactions with School Principals. Jsa, 5(2), 63-85. [in Persian]

33. Sobhaninejhad, M. \& Abniki, Z. (2012). "Identification of social responsibility indicators within the Iranian high school curriculum". New Thoughts on Education, 8(1), 59-106. [in Persian]

34. Soleymani, A. (2013). The relationship between participative management and promotion of professional competence of primary school teachers in special schools and education in Tehran. Islamic Azad University Tehran Central Branch; Tehran; Iran. [in Persian]

35. Tas, S. (2017). "The Effect of Vocational High School Administrators' Leadership Behaviors on Teacher Job Satisfaction". Universal Journal of Educational Research, 5(11), 2092 -2100.

36. Toropova, A., Myrberg, E., \& Johansson, S. (2021). Teacher job satisfaction: the importance of school working conditions and teacher characteristics. Educational review, 73(1), 71-97.

37. Tootian, S., Mehrara, A., Bigdeli, M. (2018). the relationship between personality traits and creativity with the organizational performance of educational managers' human resources in Tehran's fifth region. jiera, 12(Special Issue), 749-766. [in Persian]

38. Wright, B. E. \& Kim, S. (2004). "Participation's Influence on Job Satisfaction". Review of Public Personnel Administration, 24(1), 18-40.

39. Yaghoobpoor, S. \& Fateminezhad, M. (2017). "Comparison between job satisfaction and employee motivation with herzberg two- factor mode". New Approaches in Educational Administration, 8(1), 263-282. [in Persian] 